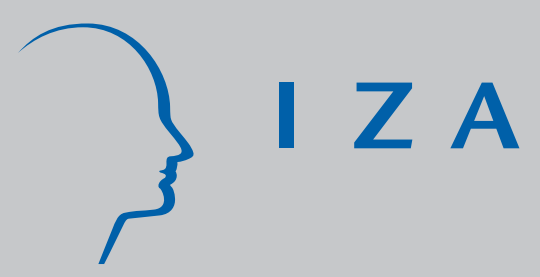

IZA DP No. 1512

The Employment Effects of J ob Creation Schemes in Germany: A Microeconometric Evaluation

Marco Caliendo

Reinhard Hujer

Stephan L. Thomsen

March 2005 


\title{
The Employment Effects of Job Creation Schemes in Germany: A Microeconometric Evaluation
}

\author{
Marco Caliendo \\ DIW Berlin and IZA Bonn \\ Reinhard Hujer \\ University of Frankfurt, \\ ZEW Mannheim and IZA Bonn \\ Stephan L. Thomsen \\ University of Frankfurt
}

\author{
Discussion Paper No. 1512 \\ March 2005
}

\author{
IZA \\ P.O. Box 7240 \\ 53072 Bonn \\ Germany \\ Phone: +49-228-3894-0 \\ Fax: +49-228-3894-180 \\ Email: iza@iza.org
}

\begin{abstract}
Any opinions expressed here are those of the author(s) and not those of the institute. Research disseminated by IZA may include views on policy, but the institute itself takes no institutional policy positions.

The Institute for the Study of Labor (IZA) in Bonn is a local and virtual international research center and a place of communication between science, politics and business. IZA is an independent nonprofit company supported by Deutsche Post World Net. The center is associated with the University of Bonn and offers a stimulating research environment through its research networks, research support, and visitors and doctoral programs. IZA engages in (i) original and internationally competitive research in all fields of labor economics, (ii) development of policy concepts, and (iii) dissemination of research results and concepts to the interested public.
\end{abstract}

IZA Discussion Papers often represent preliminary work and are circulated to encourage discussion. Citation of such a paper should account for its provisional character. A revised version may be available directly from the author. 


\section{ABSTRACT \\ The Employment Effects of Job Creation Schemes in Germany: A Microeconometric Evaluation*}

In this paper we evaluate the employment effects of job creation schemes on the participating individuals in Germany. Job creation schemes are a major element of active labour market policy in Germany and are targeted at long-term unemployed and other hard-to-place individuals. Access to very informative administrative data of the Federal Employment Agency justifies the application of a matching estimator and allows to account for individual (group-specific) and regional effect heterogeneity. We extend previous studies in four directions. First, we are able to evaluate the effects on regular (unsubsidised) employment. Second, we observe the outcome of participants and non-participants for nearly three years after programme start and can therefore analyse mid- and long-term effects. Third, we test the sensitivity of the results with respect to various decisions which have to be made during implementation of the matching estimator, e.g. choosing the matching algorithm or estimating the propensity score. Finally, we check if a possible occurrence of 'unobserved heterogeneity' distorts our interpretation. The overall results are rather discouraging, since the employment effects are negative or insignificant for most of the analysed groups. One notable exception are long-term unemployed individuals who benefit from participation. Hence, one policy implication is to address programmes to this problem group more tightly.

JEL Classification: J68, H43, C13

Keywords: evaluation, matching, sensitivity analysis, job creation schemes, long-term unemployed

Corresponding author:

Marco Caliendo

Department of Public Economics

DIW Berlin

Königin-Luise-Str. 5

14195 Berlin

Germany

Email: mcaliendo@diw.de

\footnotetext{
* This paper emerged within the research project 'Effects of Job Creation and Structural Adjustment Schemes' financed by the Institute for Employment Research (IAB).
} 


\section{Introduction}

The German labour market is plagued by persistently high unemployment in combination with a clearly separated situation on the labour markets in West and East Germany. This gets clear looking at the unemployment rate for 2003, which has been $9.3 \%$ in West and $20.1 \%$ in East Germany. The Federal Employment Agency (FEA) spends substantial amounts to overcome this unemployment problem. A particular emphasis is laid on active labour market policies (ALMP), as the spendings of 12.3 bn Euro in West Germany and 8.9 bn Euro in East Germany reflect. The main goal of ALMP is the permanent integration of unemployed persons into regular employment. ALMP were first introduced in Germany in the late 1960s and have been gradually adjusted to important changes on the labour market since then. One major reform step was the introduction of the Social Code III (Sozialgesetzbuch III) in 1998 as the legal basis for ALMP. Within that reform new instruments were introduced, competencies were decentralised and a more flexible allocation of funds has been made possible. Maybe the most important change from an evaluator's point of view was the legal anchoring of a mandatory output evaluation for all ALMP measures. As a consequence new administrative datasets have been made accessible for scientific research. ${ }^{1}$

A major element of ALMP in Germany over the last years have been job creation schemes (JCS), even though their importance is currently decreasing. JCS have often been criticised because they lack explicit qualificational elements and they might involve 'stigma effects'. ${ }^{2}$ However, it can also be argued that they are a reasonable opportunity for individuals who are not able to re-integrate into the first labour market themselves or who do not fit the criteria for other programmes, e.g. long-term unemployed or other hard-to-place individuals. The evaluation of JCS has been impossible for a long time, since datasets have either not been available or been to small to draw policy relevant conclusions. However, with the introduction of the Social Code III things have changed and give us access to a very rich administrative dataset containing more than 11,000 participants in JCS and a comparison group of nearly 220,000 non-participants. We use this data to answer the question, if JCS enhance the employment chances of participating individuals. The extensive set of available individual characteristics in combination with information on the regional labour market situation, makes the application of a matching estimator possible. Additionally, the large number of participants allows to account for several sources of effect heterogeneity.

The importance of effect heterogeneity for the evaluation of JCS in Germany has been well documented in Hujer, Caliendo, and Thomsen (2004). Basically, there are two shortcomings to that study. The first one refers to an unsatisfying outcome variable, which allows only to monitor if the individual is registered unemployed or not and does not allow to draw conclusions about the re-integration success into regular (unsubsidised) employment. A second restriction relates to the relatively short observation period after programme start, namely two years. This paper extends the

\footnotetext{
${ }^{1}$ The reform process on the German labour market is still ongoing. More reforms are implemented gradually (see 'Modern Services on the Labour Market', Bundesministerium für Wirtschaft und Arbeit (2003)). Since we focus in our empirical analysis on the time period 2000-2002, we are not going to discuss the current reforms here.

${ }^{2}$ If the programme is targeted at people with 'disadvantages', there is always a risk that a possible employer takes participation in such schemes as a negative signal concerning the expected productivity or motivation.
} 
previous analyses in four directions. First, we are able to evaluate the re-integration effects of JCS into regular (unsubsidised) employment. Second, we can monitor the employment status of participants and non-participants nearly three years after programme start. Third, we test the sensitivity of the results to various decisions which have to be made whilst implementing the matching estimator, like the choice of the matching algorithm or the estimation of the propensity score. Finally, we check if a possible occurrence of 'unobserved heterogeneity' or 'hidden bias' distorts interpretation of our results.

The focus of our analysis will be the identification of individual (group-specific) and regional effect heterogeneity. ${ }^{3}$ To do so, we separate the analysis by several characteristics and carry out the matching analysis on sub-populations. ${ }^{4}$ Men and women in West and East Germany will be the 'main groups' of our analysis. In addition, we estimate effects for eleven 'sub-groups' defined by age and unemployment duration as well as by specific characteristics indicating disadvantages on the labour market like the lack of professional training or the existence of placement restrictions due to health problems. The situation on the regional labour market might be a further source of effect heterogeneity as programme impacts may differ in regions with high underemployment when compared to prospering regions. We take that into account by evaluating the programme effects with respect to regional differences using the classification of similar and comparable labour office districts of the FEA (Blien et al. (2004)).

The remainder of this paper is organised as follows. In the following section we describe the institutional background of JCS in Germany, introduce the dataset used and present some descriptive statistics. Section 3 explains the general framework for microeconometric evaluation analysis and section 4 deals with the empirical implementation of the matching estimator. In particular we discuss the justification of the matching estimator, the estimation of the propensity scores (section 4.1) and the choice of the proper matching algorithm (section 4.2) for our situation. Section 4.3 deals with common support issues, whereas section 4.4 presents some quality indicators for the chosen matching algorithm. In section 5 we present the results for the main and sub-groups as well as for the regional clusters. Additionally, we also test the sensitivity of our estimates with respect to unobserved heterogeneity. The final section concludes and gives some policy recommendations.

\section{Institutional Background, Dataset and Selected Descriptives}

\subsection{Institutional Background}

JCS have been the second most important programme (after vocational training) of ALMP in Germany in the last years with respect to the number of participants. JCS can be supported if they provide the last chance to stabilise and qualify unemployed individuals for later re-integration into

\footnotetext{
${ }^{3}$ In a companion paper, we concentrate on sectoral heterogeneity (Caliendo, Hujer, and Thomsen, 2004b).

${ }^{4}$ There are basically two ways to put greater emphasis on specific variables. One can either find variables in the comparison group who are identical with respect to these variables (see e.g. Puhani (1998) or carrying out matching on sub-populations (see e.g. Heckman, Ichimura, and Todd (1997) or Heckman, Ichimura, Smith, and Todd (1998)).
} 
regular employment. ${ }^{5}$ JCS should support activities, which are additional in nature and for the collective good. Additional in nature means, that the activities could not be executed without the subsidy. To prevent substitution effects and windfall gains, measures with a predominantly commercial purpose have been excluded up to January 2002, when the legal requirements have been relaxed by a law amendment ('Job-AQTIV-Gesetz'). The majority of activities is conducted in the public and non-commercial sector. Since JCS are co-financed measures, support is obtained as a wage subsidy to the employer, covering $30 \%$ to $75 \%$ of the costs, which is usually paid for twelve months. Exceptions can be made for a higher subsidy-quota (up to 100\%) and a longer duration (up to 24 months) for persons with strong labour market disadvantages or projects of high priority (see below). Before January 2002, potential participants had to be long-term unemployed (for more than one year) or unemployed for at least six of the last twelve months before participation. Furthermore, they had to fulfil the requirements for entitlement of unemployment compensation. In addition, the local placement officers were allowed to place up to five percent of the allocated individuals who did not meet these conditions (Five-Percent-Quota). Further exceptions are made for young unemployed (under 25 years) without professional training, short-term unemployed (with at least three months of unemployment) placed as tutors, and disabled who could be stabilised or qualified. ${ }^{6}$ Participants are allowed to do a practical training up to $40 \%$ of the time and a vocational training of up to $20 \%$, together no more than $50 \%$ of the programme duration. Priority should be given to projects which enhance the chances for permanent jobs, support structural improvement in social or environmental services or aim at the integration of extremely hard-to-place individuals. Participation in JCS results from placement by the local labour office. Unemployed individuals, who fulfil the eligibility criteria, can be offered a specific occupation. The responsible caseworker can cancel a running programme at any time, if the participant can be placed into regular employment. If an unemployed person rejects the offer of a JCS or if a participant denies a career counselling by the placement officer, the labour office can stop unemployment benefits at the first time for up to twelve weeks. If rejections to offers repeat, persons may lose their entitlement for unemployment benefits.

\subsection{Dataset}

The empirical analysis is based on a dataset merged from several administrative sources of the FEA. ${ }^{7}$ It contains information on all participants who have started a JCS in February 2000. The sample of non-participants was drawn from the Job-Seekers-Data-Base (BewA) in January 2000. Hence, it consists of individuals who have been eligible for participation, but have not entered those schemes in February 2000. The dataset includes numerous attributes to describe the labour market situation of the individuals. The information can be categorised into four classes: socio-demographic information, like age, gender and marital status, qualification details (work experience, professional training,

\footnotetext{
5 The legal basis of JCS is $\S \S 260-271,416$ Social Code III.

${ }^{6}$ With the 2002 amendment, all unemployed individuals can enter a JCS independently of the preceding unemployment duration, but with restriction that JCS is the only opportunity for occupation. In addition, the Five-Percent-Quota has been augmented to ten percent.

${ }^{7}$ See Caliendo, Hujer, and Thomsen (2004a) for more details on the data sources.
} 
etc.), a short labour market history (durations of last employment and unemployment spells) and particular programme information (programme sector, programme duration). Since all information originates from the same sources for participants and non-participants, the dataset provides a good basis for the construction of a valid comparison group. Furthermore, the large set of attributes enables the implementation of matching estimators for causal programme evaluation. The dataset is completed by a FEA characterisation of the regional labour market situation in the labour office districts (Blien et al.(2004)). ${ }^{8}$ The outcome variable is taken from the Employment Statistics Register ('Beschäftigtenstatistik', BSt), which contains information on the total population of all people who are registered in the social security system. These are all regularly employed persons and participants of several ALMP programmes, but no self-employed or pensioners. Since we treat only regular (unsubsidised) employment as a success, we use the programme participants master dataset ('Maßnahmeteilnehmergrunddatei', MTG) which contains information on all ALMP programmes by the FEA, to complete our outcome variable. In our analysis we treat subsidised employment or participation in ALMP programmes as a failure. Although this definition might conflict with the institutional setting, it reflects the economic point of view to measure the integration ability of JCS into regular (unsubsidised) employment. ${ }^{9}$ We observe the labour market outcome for the treatment and comparison group until December 2002. We exclude information on participants in Berlin. ${ }^{10}$ Our final sample consists of 11,151 participants and 219,622 non-participants. Previous empirical findings have shown that the effects of JCS differ with respect to region and gender (see e.g. Hujer, Caliendo, and Thomsen (2004)). Thus, we separate our analysis by these aspects, i.e. we estimate the effects separately for men and women in West and East Germany, which are the four 'main groups' of our analysis. Table 1 shows that the largest groups are women $(5,035)$ and men $(2,924)$ in East Germany. In West Germany, 2,140 men and 1,052 women have started a JCS in February 2000.

Due to the large number of observations in our sample, we are also able to analyse the programme effects for specific problem-groups of the labour market. We evaluate the effects separately for three age categories (younger than 25 years, between 25 and 50 years, and older than 50 years) and for different unemployment durations (up to 13 weeks, between 13 and 52 weeks, and for more than 52 weeks), as well as for persons without work experience, without professional training and for the counterfactual group of persons with a high educational degree (college and university graduates). Furthermore, we analyse the effects for rehabilitation attendants, and for individuals for whom the caseworkers have noted placement restrictions due to health problems. In total we get eleven 'subgroups' for whom the effects will be estimated separately in both regions and for both gender. Table 1 contains the observations in these groups, differentiated by participation status. What can be seen as most important is that nearly all groups contain a reasonable number of participants $(>100)$, allowing a proper estimation and interpretation of the effects. Groups with less than 100 observations

\footnotetext{
${ }^{8}$ We will discuss the regional information in more detail in appendix B.

${ }^{9}$ Only the first programme participation is evaluated, any participation in later programmes is viewed as an outcome of the first treatment and is defined as a failure.

10 The special situation of the labour market in the capital city would require a separate evaluation of the effects. However, the small number of participants aggravates the interpretation of the results. So we decided to exclude Berlin from our analysis.
} 
Tab. 1: Number of Observations in Main and Sub-Groups

\begin{tabular}{|c|c|c|c|c|c|c|c|c|}
\hline \multirow[b]{3}{*}{ Groups } & \multicolumn{4}{|c|}{ West Germany } & \multicolumn{4}{|c|}{ East Germany $^{1}$} \\
\hline & \multicolumn{2}{|c|}{ Men } & \multicolumn{2}{|c|}{ Women } & \multicolumn{2}{|c|}{ Men } & \multicolumn{2}{|c|}{ Women } \\
\hline & Part. & $\begin{array}{l}\text { Non- } \\
\text { Part. }\end{array}$ & Part. & $\begin{array}{l}\text { Non- } \\
\text { Part. }\end{array}$ & Part. & $\begin{array}{l}\text { Non- } \\
\text { Part. }\end{array}$ & Part. & $\begin{array}{l}\text { Non- } \\
\text { Part. }\end{array}$ \\
\hline Total (Main group) & 2,140 & 44,095 & 1,052 & 34,227 & 2,924 & 64,788 & 5,035 & 76,512 \\
\hline \multicolumn{9}{|l|}{ Age (in years) } \\
\hline$<25$ years & 458 & 4,102 & 182 & 2,443 & 240 & 8,743 & 148 & 4,864 \\
\hline $25-50$ years & 1,337 & 23,560 & 709 & 19,732 & 1571 & 35,927 & 3,342 & 44,329 \\
\hline$>50$ years & 345 & 16,433 & 161 & 12,052 & 1,113 & 20,118 & 1,545 & 27,319 \\
\hline \multicolumn{9}{|l|}{ Unemployment duration (in weeks) } \\
\hline$<13$ weeks & 558 & 12,198 & 237 & 7561 & 578 & 22,003 & 575 & 12,447 \\
\hline $13-52$ weeks & 744 & 13,909 & 403 & 12,235 & 1,248 & 22,864 & 1,970 & 26,657 \\
\hline$>52$ weeks & 838 & 17,988 & 412 & 14,431 & 1,098 & 19,921 & 2,490 & 37,408 \\
\hline Without professional experience & 273 & 3,281 & 159 & 2,548 & 293 & 7,023 & 498 & 7945 \\
\hline Without professional training & 1,340 & 21,659 & 476 & 17,093 & 837 & 14,966 & 1,121 & 19,776 \\
\hline With high degree & 112 & 1,486 & 146 & 1,165 & 146 & 2,682 & 191 & 1,619 \\
\hline Rehabilitation attendant & 111 & 2,763 & 44 & 1,063 & 218 & 4,849 & 156 & 3,520 \\
\hline With placement restrictions & 354 & 9,516 & 148 & 5,993 & 394 & 10,470 & 376 & 9,121 \\
\hline
\end{tabular}

${ }^{1}$ Observations from the labour office districts of Berlin are excluded.

are excluded from the analysis.

Furthermore, we evaluate the programme effects with respect to regional differences using the classification of similar and comparable labour office districts of the FEA (Blien et al. (2004)). This classification assigns the 181 labour office districts in Germany to twelve comparable clusters, which can be summarised into five clusters for strategic purposes. We use the coarser classification for strategic purposes for Western Germany (four clusters). Since all (except one) labour office districts in East Germany belong to the first cluster for strategic purposes, we use the finer classification of three clusters for Eastern Germany. Table B.1 in appendix B describes the characteristics of each cluster and presents the number of labour office districts as well as the number of participants in each cluster. The largest number of observations can be found in cluster Ib, where $53.1 \%$ of all female and $36.1 \%$ of all male participants are located. The smallest number of participants is found in cluster IV with only $3.6 \%$ of the male and $1.3 \%$ of the female participants.

\subsection{Selected Descriptives for the Main Groups and the Regional Clusters}

Descriptives for the Main Groups: Table A.1 in appendix A shows selected descriptive statistics for the 'main groups' differentiated by participation status. The variables are measured at the begin of the programme in February 2000. Whereas the numbers from table 1 have shown that more individuals participate in East Germany, the individual attributes show regional differences, too, and we will describe the most important ones. First of all it is worth noting that participants in West Germany are on average younger than non-participants. While participating men in West Germany are on average 37.2 years old at programme begin, the non-participants are on average 43.2 years old. The same proportion holds for women in West Germany, where the participants are 37.8 years and the non-participants 43.3 years. In contrast to that, participating men in East 
Germany are older (44.5 years vs. 41.7 years) than non-participants, whereas participating women in East Germany are approximately the same age (44 years) as their respective counterparts in the comparison group. Clear differences between participants and non-participants can be found in the number of (unsuccessful) placement propositions, which is much higher for participants and can be seen as an indicator for a more problematic placement process of the participants. Participating men (women) in West Germany have on average 7.7 (6.9) placement propositions, whereas the corresponding number in the group of non-participants is only 3.6 (3.0). In East Germany we get a similar picture, where participating men (women) have on average 6.1 (5.4) placement propositions, whereas non-participating men (women) have 3.0 (2.8). However, concluding from these figures that allocation of individuals to JCS is target-oriented to specific problem groups of the labour market, is not straightforward. This becomes clear when looking at the variable placement restrictions. It indicates the reduced placement opportunities due to individual health restrictions noted by the local placement officers. It reflects the caseworker's assessment of the individual's situation and is often used to identify the need of an individual for further assistance. It is quite interesting to note, that the share of people with placement restrictions is higher in the group of non-participants independently of region and gender. Additionally, individuals in the treatment group have in general fewer health restrictions, which complements the above statement. Another interesting difference between East and West Germany becomes obvious regarding the qualification variables. In the Western part the majority of participants does not have a completed professional training (62\% of the men, $45 \%$ of the women), whereas the numbers in East Germany are much lower. In East Germany only around $28 \%$ (22\%) of the participating men (women) do not have a completed professional training. Within the regions and gender, no large differences emerge between participants and non-participants. One exception are men in West Germany, where the share of non-participants without professional training lies around $49 \%$ and is much lower compared to the share of participants. With respect to work experience, no significant differences can be found between participants and non-participants in East Germany - the share of people with work experience is around 90\% - whereas in West Germany participating men $(87 \%)$ and women $(85 \%)$ have on average less work experience compared to their counterparts in the comparison group (men and women: 93\%). Clearly, both points (qualification and work experience) have to be seen in conjunction with the age of participants which is lower in West Germany. Turning back to table 1 shows, that the share of participants below 25 years is $21.4 \%$ $(17.3 \%$ ) for men (women) in West Germany and only 8.2\% (2.9\%) for men (women) in East Germany. This may indicate a different purpose of JCS in both regions, where JCS are more target-oriented (e.g. for young unemployed without professional training) in West-Germany and also used to relieve the tense situation on the labour market in East Germany.

Descriptives for the Regional Clusters: As mentioned above we differentiate our analysis between five clusters of labour office districts, where cluster I districts are sub-categorised into three classes. This leaves us with seven clusters for the analysis for which the effects will be estimated 
separately. ${ }^{11}$ Tables A.2 (clusters Ia, Ib and Ic) and A.3 (clusters II-V) in appendix A present selected descriptives for participants and non-participants in these clusters. Starting with the results for the clusters in East Germany, it is quite interesting to note that the number of placement propositions varies considerably between the clusters. For example, participating men in cluster Ia (worst labour market conditions in East Germany) have on average 5.1 placement propositions, whereas participating men in cluster Ic (best labour market conditions in East Germany) have on average 7.2 propositions. For women in these clusters the same tendency emerges with 4.8 placement propositions in cluster Ia and 6.3 propositions in cluster Ic. Additionally, it becomes obvious that independently of gender, in districts with a bad labour market environment the average programme duration is longer than in districts with a better environment. Men and women in districts of cluster Ia remain in programmes on average for 336.4 and 345.2 days, whereas they remain only 295.2 and 304.9 day in cluster Ic. Considering the shares of participants without professional training shows, that in a better labour market environment a higher share of participants belong to this group. Taken together, this may be seen as an indication for different purposes in the implementation of programmes. In labour office districts, where the labour market has only the slightest dynamics and is also characterised by high underemployment, JCS are used to relieve this tense labour market situation. In regions with more dynamics, allocation to JCS is more likely to follow the postulations from the law and hence is more target-oriented to specific problem groups of the labour market. Turning to the results for clusters II to $\mathrm{V}$ in table A.3 shows that this finding does not hold for participants in the primarily West German districts. Here, the share of persons without professional training is higher in districts with worse opportunities. However, this may be caused by the fact that in regions with better labour market conditions and consequently lower unemployment other programmes (e.g. vocational training) are offered. Therefore, the share of participants without professional training is lower in those districts. Additionally, for cluster II to V it can also be seen that the share of short-term unemployed persons increases with the situation on the labour market. Whereas in cluster II approximately $22 \%(19 \%)$ of the participating and non-participating men (women) are short-term unemployed, the share of short-term unemployed in cluster $\mathrm{V}$ ranges from $24.8 \%$ (participating women) to nearly $40 \%$ (non-participating men).

\section{The Estimation of Treatment Effects with Matching Estimators}

The Potential Outcome Framework and Selection Bias Since we work with non-experimental data, we have to deal with some identifying issues. As we consider only one specific programme compared to non-participation, we can use the potential outcome framework with two potential outcomes $Y^{1}$ (individual receives treatment) and $Y^{0}$ (individual does not receive treatment). ${ }^{12}$ The actually observed outcome for any individual $i$ can be written as: $Y_{i}=Y_{i}^{1} \cdot D_{i}+\left(1-D_{i}\right) \cdot Y_{i}^{0}$, where $D \in\{0,1\}$ is a binary treatment indicator. The treatment effect for each individual $i$ is then

\footnotetext{
${ }^{11}$ See appendix B for additional information on the classification.

12 The potential outcome framework is variously attributed to Fisher (1935), Neyman (1935), Roy (1951), Quandt $(1972,1988)$ or Rubin $(1974)$, but most often it is just called the Roy-Rubin-model (RRM).
} 
defined as the difference between her potential outcomes $\Delta_{i}=Y_{i}^{1}-Y_{i}^{0}$. Since there will be never an opportunity to estimate individual effects with confidence, we have to concentrate on population averages of gains from treatment. The most prominent evaluation parameter is the so called average treatment effect on the treated (ATT), which focuses explicitly on the effects on those for whom the programme is actually intended. It is given by:

$$
A T T=E(\Delta \mid D=1)=E\left(Y^{1} \mid D=1\right)-E\left(Y^{0} \mid D=1\right) .
$$

In the sense that this parameter focuses directly on actual treatment participants, it determines the realised gross gain from the programme and can be compared with its costs, helping to decide whether the programme is a success or not (Heckman, LaLonde, and Smith, 1999). Given equation (1) the problem of selection bias is straightforward to see, since the second term on the right hand side is unobservable. If the condition $E\left(Y^{0} \mid D=1\right)=E\left(Y^{0} \mid D=0\right)$ holds, we can use the non-participants as an adequate comparison group. However, with non-experimental data it will usually not hold. Consequently, estimating the ATT by the difference in the subpopulation means of participants $E\left(Y^{1} \mid D=1\right)$ and non-participants $E\left(Y^{0} \mid D=0\right)$ will lead to a selection bias, since participants and non-participants are selected groups that would have different outcomes even in absence of the programme. This bias may come from observable factors like age or skill differences or unobservable factors like motivation. For both cases different estimation strategies are available. ${ }^{13}$ If we are willing to assume that selection occurs on observed characteristics only, the matching estimator is an appealing choice. Its basic idea is to search from a large group of non-participants those individuals who are similar to the treated group in all relevant (observable) characteristics. ${ }^{14}$

How Does Matching Solve the Evaluation Problem? Matching is based on the identifying assumption that, conditional on some covariate $X$, the outcome $Y$ is independent of $D$. It is well known that matching on $X$ can become hazardous when $X$ is of high dimension ('curse of dimensionality'). To deal with this dimensionality problem, Rosenbaum and Rubin (1983) suggest the use of balancing scores $b(X)$, i.e. functions of the relevant observed covariates $X$ such that the conditional distribution of $X$ given $b(X)$ is independent of the assignment to treatment, that is $X \amalg D \mid b(X)$. For participants and non-participants with the same balancing score, the distributions of the covariates $X$ are the same, i.e. they are balanced across the groups. The propensity score $P(X)$, i.e. the probability of participating in a programme is one possible balancing score. It summarises the information of the observed covariates $X$ into a single index function. The propensity score can be seen as the coarsest balancing score whereas $X$ is the finest (Rosenbaum and Rubin, 1983). The authors also show that if treatment assignment is strongly ignorable given $X$, it is also strongly ignorable given any balancing score. Hence, it is sufficient to assume that (in the notation of Dawid (1979)):

Assumption 1 Unconfoundedness for Controls given the Propensity Score:

$$
Y^{0} \amalg D \mid P(X),
$$

\footnotetext{
${ }^{13}$ See Heckman, LaLonde, and Smith (1999), Angrist and Krueger (1999) or Blundell and Costa-Dias (2002) for overviews.

${ }^{14}$ See Imbens (2004) or Smith and Todd (2005) for recent overviews regarding matching methods.
} 
where $\amalg$ denotes independence. If assumption 1 is fulfilled, the non-participant outcomes have, conditional on $P(X)$, the same distribution that participants would have experienced if they had not participated in the programme (Heckman, Ichimura, and Todd, 1997). Similar to randomisation in a classical experiment, matching balances the distributions of all relevant pre-treatment characteristics $X$ in the treatment and comparison group, and thus achieves independence between the potential outcomes and the assignment to treatment. Hence, if the mean exists,

$$
E\left(Y^{0} \mid X, D=1\right)=E\left(Y^{0} \mid X, D=0\right)=E\left(Y^{0} \mid X\right)
$$

and the missing counterfactual mean can be constructed from the outcomes of non-participants. In order for both sides of the equations to be well defined simultaneously for all $X$, it is usually additionally assumed that

\section{Assumption 2 Weak Overlap:}

$$
\operatorname{Pr}(D=1 \mid X)<1
$$

for all $X$. This implies that the support of $X$ is equal in both groups, i.e. $S=\operatorname{Support}(X \mid D=1)=$ $\operatorname{Support}(X \mid D=0)$. These assumptions are sufficient for identification of (1), because the moments of the distribution of $Y^{1}$ for the treated are directly estimable. ${ }^{15}$ The method of matching can also be used to estimate the ATT at some points $X=x$, where $x$ is a particular realisation of $X$ :

$$
A T T(X=x)=E(\Delta \mid X=x, D=1)=E\left(Y^{1} \mid X=x, D=1\right)-E\left(Y^{0} \mid X=x, D=1\right) .
$$

This parameter measures the mean treatment effect for persons who were randomly drawn from the population of the treated given a specific realisation of certain characteristics $X$. This is of particular interest for us, since we want to estimate the effects for sub-groups, like long-term unemployed persons or individuals without work experience.

\section{Implementation of the Matching Estimator}

After having decided to use matching estimators for evaluation purposes, the researcher is confronted with several questions regarding the implementation of these estimators. ${ }^{16}$ Every evaluation task requires a careful consideration of the available choices for the given situation. Hence, we will discuss the implementation and justification of the matching estimator in our context in the next subsections. We start with the plausibility of CIA in our context. Since the number of covariates in the data makes the use of covariate matching unfeasible, we rely on propensity score matching. To do so, we have to consider the correct model and the choice of relevant variables for the participation probability. Following that, we choose one matching algorithm to be used in the further analysis. Subsections 4.3 and 4.4 will be concerned with common support and matching quality issues.

\footnotetext{
${ }^{15}$ To identify the average treatment effect (ATE), additional assumptions are required.

${ }^{16}$ Caliendo (2005) provides an extensive overview of the issues arising when implementing matching estimators. He also discusses efficiency issues when choosing between different matching algorithms.
} 


\subsection{Plausibility of CIA and Propensity Score Estimation}

Before estimating the propensity scores, we have to consider the plausibility of the CIA in our context briefly. As already noted, for the CIA to be fulfilled we need to condition on all variables that jointly influence the participation decision and the outcome variable. Our dataset (see section 2.2) contains a rich set of variables, including socio-demographic variables, information about the qualificational background and the labour market history of individuals. The latter point is most important since previous empirical studies have emphasised the importance of the labour market history (see Heckman, LaLonde, and Smith (1999)). Finally, the situation on the regional labour market is accounted for by using the FEA-clusters as described in section 2.3. Given this informative dataset we argue henceforth that the CIA holds. We test the sensitivity of our estimates to this assumption using a bounding analysis in section 5 .

Estimation of the propensity scores requires two choices to be made: First, the choice of an adequate model and second, the selection of variables to be included in this model. Little advice is available regarding which functional form to use (see e.g. Smith (1997)). In principle any discrete choice model can be used. Preference for logit or probit models (compared to linear probability models) derives from the well-known shortcomings of the linear probability model. For the binary treatment case, where we estimate the probability of participation vs. non-participation, logit and probit models usually yield similar results. Hence, the choice is not too critical. Since the logit distribution has more density mass in the bounds that reflects our situation better, it will be used for estimation.

More advice is available regarding the inclusion (or exclusion) of covariates in the propensity score model. The matching strategy builds on CIA, requiring that the outcome variable(s) must be independent of treatment conditional on the propensity score. Therefore, implementing matching requires choosing a set of variables $X$ that credibly satisfies this condition. Only variables that simultaneously influence the participation decision and the outcome variable should be included. Hence, economic theory, a sound knowledge of previous research and also information about the institutional settings should guide the researcher in building up the model (see e.g. Smith and Todd (2005) or Sianesi (2004)). Furthermore, it should be clear that only variables that are unaffected by participation (or the anticipation of it) should be included in the model. Economic theory gives some guidance on which variables to choose. The accumulated evidence in the evaluation literature points out that the labour market history of individuals and the regional labour market environment are crucial variables to be included in the estimation (Heckman, LaLonde, and Smith, 1999). In cases of uncertainty of the proper specification, the question might arise if it is better to include too many rather than too few variables. Bryson, Dorsett, and Purdon (2002) note that there are two reasons why over-parameterised models should be avoided. First, it may be the case that including extraneous variables in the participation model exacerbate the support problem. Second, although the inclusion of insignificant variables will not bias the estimates or make them inconsistent, it may increase their variance. Rubin and Thomas (1996) on the other hand recommend against 'trimming' models in the name of parsimony. They argue that a variable should only be excluded from analysis if there is consensus that the variable is either unrelated to the outcome or not a proper covariate. By these 
Tab. 2: Hit-Rates and Pseudo- $R^{2}$ for Different Propensity Score Specifications ${ }^{1}$

\begin{tabular}{|c|c|c|c|c|c|c|c|c|c|c|c|}
\hline \multirow{2}{*}{\multicolumn{4}{|c|}{$\begin{array}{c}\text { Specification } \\
\text { (Sets of Variables included) }\end{array}$}} & \multicolumn{4}{|c|}{ West Germany } & \multicolumn{4}{|c|}{ East Germany } \\
\hline & & & & \multicolumn{2}{|c|}{ Men } & \multicolumn{2}{|c|}{ Women } & \multicolumn{2}{|c|}{ Men } & \multicolumn{2}{|c|}{ Women } \\
\hline $\begin{array}{c}\text { Socio- } \\
\text { Demogr. }\end{array}$ & $\begin{array}{l}\text { Qualifica- } \\
\text { tion }^{3}\end{array}$ & Career ${ }^{4}$ & Region ${ }^{5}$ & $\begin{array}{l}\text { Hit- } \\
\text { Rate }\end{array}$ & $R^{2}$ & $\begin{array}{l}\text { Hit- } \\
\text { Rate }\end{array}$ & $R^{2}$ & $\begin{array}{l}\text { Hit- } \\
\text { Rate }\end{array}$ & $R^{2}$ & $\begin{array}{l}\text { Hit- } \\
\text { Rate }\end{array}$ & $R^{2}$ \\
\hline \multirow[t]{4}{*}{$\mathrm{x}$} & & & & 55.20 & 0.036 & 64.51 & 0.050 & 44.46 & 0.014 & 54.47 & 0.019 \\
\hline & $\mathbf{x}$ & & & 61.03 & 0.033 & 76.19 & 0.036 & 59.10 & 0.014 & 67.29 & 0.013 \\
\hline & & $\mathrm{x}$ & & 73.21 & 0.106 & 79.45 & 0.130 & 76.64 & 0.106 & 72.70 & 0.097 \\
\hline & & & $\mathrm{x}$ & 54.00 & 0.000 & 81.67 & 0.001 & 63.69 & 0.000 & 73.95 & 0.000 \\
\hline $\mathrm{x}$ & $\mathrm{x}$ & & & 62.60 & 0.062 & 67.29 & 0.076 & 58.12 & 0.030 & 55.18 & 0.030 \\
\hline $\mathrm{x}$ & & $\mathbf{x}$ & & 68.81 & 0.122 & 73.03 & 0.153 & 74.56 & 0.116 & 72.20 & 0.105 \\
\hline \multirow[t]{4}{*}{$\mathbf{x}$} & & & $\mathbf{x}$ & 55.21 & 0.036 & 65.31 & 0.051 & 45.64 & 0.014 & 54.11 & 0.019 \\
\hline & $\mathrm{x}$ & $\mathbf{x}$ & & 69.74 & 0.123 & 78.09 & 0.153 & 75.36 & 0.110 & 72.61 & 0.106 \\
\hline & $\mathrm{x}$ & & $\mathbf{x}$ & 61.40 & 0.033 & 74.63 & 0.037 & 55.98 & 0.014 & 67.60 & 0.013 \\
\hline & & $\mathrm{x}$ & $\mathrm{x}$ & 72.62 & 0.106 & 77.01 & 0.133 & 76.26 & 0.106 & 72.81 & 0.098 \\
\hline $\mathrm{x}$ & $\mathrm{x}$ & $\mathrm{x}$ & & 70.65 & 0.138 & 75.53 & 0.174 & 74.28 & 0.122 & 72.18 & 0.113 \\
\hline $\mathrm{x}$ & $\mathrm{x}$ & & $\mathbf{x}$ & 62.61 & 0.062 & 67.26 & 0.077 & 57.94 & 0.030 & 55.28 & 0.030 \\
\hline \multirow[t]{2}{*}{$\mathbf{x}$} & & $\mathbf{x}$ & $\mathrm{x}$ & 68.97 & 0.123 & 73.23 & 0.157 & 74.51 & 0.117 & 72.12 & 0.106 \\
\hline & $\mathrm{x}$ & $\mathrm{x}$ & $\mathrm{x}$ & 69.99 & 0.124 & 77.51 & 0.156 & 75.12 & 0.111 & 72.69 & 0.107 \\
\hline $\mathrm{x}$ & $\mathrm{x}$ & $\mathrm{x}$ & $\mathrm{x}$ & 70.60 & 0.139 & 75.70 & 0.177 & 74.20 & 0.122 & 72.24 & 0.114 \\
\hline \multicolumn{12}{|c|}{$\begin{array}{l}{ }^{1} \text { Hit-rates are computed in the following way: If the estimated propensity score is larger than the sample proportion of persons } \\
\text { taking treatment, i.e. } \hat{P}(X)>\bar{P} \text {, observations are classified as '1'. If } \hat{P}(X) \leq \bar{P} \text { observations are classified as '0'. } \\
2 \text { Socio-demographic variables include age, age }{ }^{2} \text {, marital status, number of children, nationality (german=1) and health restric- } \\
\text { tions. } \\
{ }^{3} \text { Qualification variables include professional training, occupational group, professional rank and work experience. } \\
4 \text { Career variables include duration of last employment and unemployment, number of placement propositions, last contact to } \\
\text { job center, rehabilitation attendants, placement restrictions and previous labour market programmes. } \\
5 \text { Regional variables consist of the seven clusters defined by the FEA as discussed in } 2.3 \text {. }\end{array}$} \\
\hline
\end{tabular}

criteria, there are both reasons for and against including all covariates available.

But clearly, there are also some formal (statistical) tests which can be used. Table 2 contains the results for two tests, namely the hit-rate and the pseudo- $R^{2}$. With the 'hit or miss'-method or prediction rate metric (suggested by Heckman, Ichimura, Smith, and Todd (1998) and Heckman and Smith (1999)), variables are chosen to maximise the within-sample correct prediction rates, assuming that the costs for the misclassification are equal for the two groups (Heckman, Ichimura, and Todd, 1997). ${ }^{17}$ This method classifies an observation as ' 1 ' if the estimated propensity score is larger than the sample proportion of persons taking treatment, i.e. $\hat{P}(X)>\bar{P}$, and else as ' 0 '. The pseudo- $R^{2}$ indicates how well the regressors $X$ explain the participation probability.

Both statistics have been estimated for several specifications of the model. We have started with base specifications, containing only the variables of one of the four above mentioned categories. Using this as a starting point, we added another category of variables. For example, the first line of table 2 shows the results for a model specification where only the socio-demographic variables are included. The results in line 5 are for a model with socio-demographic and qualificational variables. Testing all possible combinations of two and three categories and finally using all information gives us 15 specifications for the four main groups. One shortcoming of such statistical tests becomes obvious from the results. If we take for example the results for women in West Germany we see

\footnotetext{
${ }^{17}$ See e.g. Breiman, Friedman, Olsen, and Stone (1984) for theory and Heckman, Ichimura, Smith, and Todd (1998) or Smith and Todd (2005) for applications.
} 
that the best hit-rate $(81.7 \%)$ is achieved by only including the regional dummy variables. With the full specification we achieve only a hit-rate of $75.7 \%$. Following that rule would mean that we should estimate the propensity score solely based on the model with regional dummy variables. This makes no economic sense since obviously important characteristics, e.g. age and qualification variables, would be excluded. It has to be kept in mind that the main purpose of the propensity score estimation is not to predict selection into treatment as well as possible but to balance all covariates (Augurzky and Schmidt, 2000). The Pseudo- $R^{2}$ shows that the full specification does the best job in explaining the participation probability. For the other three groups the findings are similar. The full specification does the best job in terms of $R^{2}$. However, even though the hit-rates are above $70 \%$ for the full specification, there are some specifications with higher hit-rates.

Considering these findings and bearing in mind that we see no economic reasons for excluding sets of variables, we use the full specification for the estimation of the propensity scores. Table A.4 in appendix A contains the results of the propensity score estimation. Looking at this table clarifies that the influence of variables on the participation probability differs by regions and gender. The coefficients of the socio-demographic variables show that the participation probability of men in West Germany decreases with age, while in East Germany older men and women are more likely to participate. This indicates once again the slightly different purpose of the programmes in East and West Germany. Especially in East Germany, JCS function as a relief for the labour market and are used as a bridge to retirement. Furthermore, it has to be noted that Germans are more likely to participate than foreigners. This may be due to the fact that other measures of ALMP (e.g. language courses) are preferred for foreigners. Health restrictions also increase the individual participation probability independently of the region which indicates an allocation according to the definitions by law.

The coefficients for the qualification characteristics emphasise gender specific differences in the allocation. A higher qualification (compared to the reference category "without completed professional training and common-school exam') increases the participation probability for women in both parts, while the effects for men are insignificant or negative. It can be assumed that it is for unemployed women with higher qualification harder than for higher qualified unemployed men to end their unemployment and so they are more likely to participate in JCS. Previous work experience reduces the participation probability for all groups. This was expected, since work experience is generally an important criterion for placement into regular employment. As unemployment duration is an eligibility criterion for participation, its influence is of major importance. We included unemployment duration in three categories and the participation probability increases with unemployment duration. The number of (unsuccessful) placement propositions is an indicator for bad labour market opportunities. A higher number of placement propositions corresponds to a higher participation probability, which indicates that allocation is done according to the law. A last interesting point to note is that placement restrictions annotated by the caseworker harm the participation probability. This is somewhat surprising, because JCS should also be offered to these groups. The coefficients for the regional context are in reference to the labour office districts with the best (in relation to the 
region) labour market environment. The coefficients are insignificant for women in East Germany. For men in East Germany we find a significant negative effect for individuals from clusters Ib and Ic. Living in labour office districts belonging to cluster II, III and IV (II, III) reduces the participation probability for women (men) in West Germany (compared to cluster V). We will use the estimated propensity scores in the following to implement the matching estimator.

\subsection{Choosing the Matching Algorithm}

After having specified the propensity score model, the next choice to be made concerns the matching algorithm to be used. Several algorithms have been suggested in the literature. Good overviews can be found in Heckman, Ichimura, Smith, and Todd (1998), Smith and Todd (2005) or Caliendo (2005). Clearly, all approaches should yield asymptotically the same results, because with growing sample size all of them become closer to comparing only exact matches (Smith, 2000). However, in small samples the choice of the matching approach can be important (Heckman, Ichimura, and Todd, 1997). All matching estimators contrast the outcome of a treated individual with the outcome of comparison group members. However, the estimators differ not only in the definition of the neighbourhood for each treated individual and the handling of the common support problem, but also with respect to the weights given to these neighbours. Usually a trade-off between bias and variance arises. First, one has to decide on how many non-treated individuals to match to a single treated individual. Nearest-neighbour (NN) matching only uses the participant and its closest neighbour. Therefore it minimises the bias but might also involve an efficiency loss, since a large number of close neigbours is disregarded. Clearly, NN matching faces the risk of bad matches, if the closest neighbour is far away. This can be avoided by using caliper matching, i.e. imposing a tolerance on the maximum distance in the propensity scores allowed. Kernel-based matching on the other hand uses more (all) non-participants for each participant, thereby reducing the variance but possibly increasing the bias. Finally, using the same non-treated individual more than once (NN matching with replacement) can possibly improve the matching quality, but increases the variance. ${ }^{18}$ Kernel matching is not feasible for our estimation, since the computing time is too high. However, to see if the inclusion of more comparison units for the construction of the counterfactual outcome has influence on the estimated effects, we also use 'oversampling' methods. This form of matching involves a trade-off between variance and bias, too. It trades reduced variance, resulting from using more information to construct the counterfactual for each participant, with increased bias that results from poorer matches on average (Smith and Todd, 2005). ${ }^{19}$

\footnotetext{
18 This is of particular interest with data where the distribution of the propensity score is very different in the treatment and the comparison group. For example if we have a lot of treated individuals with high propensity scores, but only few comparison individuals with high propensity scores, we get bad matches as some of the high-score participants will get matched to low-score non-participants. This can be overcome by allowing replacement, which in turn reduces the number of distinct participants used to construct the counterfactual outcome and thereby increases the variance of the estimator (Smith and Todd, 2005). Another problem which is related to NN matching without replacement is that the estimates depend on the order in which observations get matched.

${ }^{19}$ When using oversampling, one has to decide how many matching partners $m$ should be chosen for each individual $i$ and which weight should be assigned to them. We will use uniform weights, that is all the $m$ comparison individuals within set $A_{i}$ receive the weight $\frac{1}{m}$, whereas all other individuals from the comparison group receive the weight zero.
} 
Tab. 3: The Effects in the Main Groups for Different Matching Algorithms ${ }^{1,2}$

\begin{tabular}{|c|c|c|c|c|c|c|}
\hline \multirow{2}{*}{$\begin{array}{l}\text { West Germany } \\
\text { Matching Algorithm }\end{array}$} & \multicolumn{3}{|c|}{ Men } & \multicolumn{3}{|c|}{ Women } \\
\hline & Effect & S.E. & Obs. ${ }^{3}$ & fect & S.E. & Obs. $^{3}$ \\
\hline \multirow{2}{*}{$\begin{array}{l}\text { NN without replacement } \\
\text { caliper } 0.01\end{array}$} & -0.0005 & 0.0108 & 2,132 & 0.0554 & 0.0200 & 1,028 \\
\hline & -0.0028 & 0.0137 & 119 & 0.0451 & 0.0213 & 975 \\
\hline caliper 0.02 & 9 & 8 & 23 & 59 & 58 & 980 \\
\hline & & & & & & 002 \\
\hline \multirow{4}{*}{$\begin{array}{l}\text { NN with replacement } \\
\text { caliper } 0.01 \\
\text { caliper } 0.02 \\
\text { caliper } 0.05\end{array}$} & & 0.0 & 40 & 0.0504 & 0.0231 & 052 \\
\hline & 12 & 0.0 & 32 & 0.0504 & 0.0233 & 051 \\
\hline & & 0.0 & 39 & 0.0504 & 0.0211 & 052 \\
\hline & & & & & & \\
\hline \multicolumn{7}{|l|}{ Oversampling } \\
\hline $2 \mathrm{NN}$ & 3 & & 0 & 66 & 21 & 1,052 \\
\hline $5 \mathrm{~N}$ & & & & & & 052 \\
\hline $10 \mathrm{NN}$ & & 0.0100 & & & 0.0180 & \\
\hline \multicolumn{2}{|l|}{ East Germany } & \multicolumn{2}{|l|}{ Men } & \multicolumn{3}{|c|}{ Women } \\
\hline Matching Algorithm & Effect & S.E. & Obs. ${ }^{3}$ & Effect & S.E. & Obs. ${ }^{3}$ \\
\hline \multirow{4}{*}{$\begin{array}{l}\text { NN without replacement } \\
\text { caliper } 0.01\end{array}$} & -0.0291 & 0.0080 & 2,924 & -0.0135 & 0.0075 & 5,032 \\
\hline & .0289 & 0.0 & 2,908 & -0.0137 & 0.0070 & 5,026 \\
\hline & -0.0287 & 0.0088 & 2,923 & -0.0135 & 0.0064 & 5,027 \\
\hline & & 0.0 & 24 & -0.0135 & 76 & 027 \\
\hline \multirow{4}{*}{$\begin{array}{l}\text { NN with replacement } \\
\text { caliper } 0.01 \\
\text { caliper } 0.02 \\
\text { caliper } 0.05\end{array}$} & 94 & 0.0112 & 2,924 & -0.0193 & 0.0063 & 5,035 \\
\hline & 94 & 0.0086 & 2,924 & -0.0191 & 0.0069 & 5,031 \\
\hline & .0294 & 0.0092 & 2,924 & -0.0193 & 0.0075 & 5,032 \\
\hline & -0.0294 & 0.0105 & 2,924 & -0.0193 & 0.0081 & 5,034 \\
\hline \multicolumn{7}{|l|}{ Oversampling } \\
\hline $2 \mathrm{NN}$ & 50 & 0.0090 & 2,924 & -0.0128 & 0.0073 & 5,035 \\
\hline $5 \mathrm{NN}$ & .0237 & 0.0065 & 2,924 & -0.0101 & 0.0055 & 5,035 \\
\hline $10 \mathrm{NN}$ & -0.0249 & 0.0076 & 2,924 & -0.0106 & 0.0038 & 5,035 \\
\hline \multicolumn{7}{|c|}{$\begin{array}{l}\text { Bold letters indicate significance at the } 1 \% \text {-level, italic letters refer to the } \\
5 \% \text {-level. Standard errors are bootstrapped with } 50 \text { replications. } \\
\text { Nearest Neighbour (NN) matching without replacement uses each non- } \\
\text { participant only once, whereas with NN matching with replacement each non- } \\
\text { participant can be used repeatedly. Caliper defines the maximal allowed dif- } \\
\text { ference in the propensity score of participants and matched non-participants. } \\
\text { Matching is implemented with the Stata module PSMATCH2 by Leuven and } \\
\text { Sianesi (2003). } \\
\text { Obs. is the number of participants after matching. }\end{array}$} \\
\hline
\end{tabular}

This brief discussion makes clear that even with NN matching several alternatives emerge. It seems reasonable to try a number of approaches and test the sensitivity of the results with respect to the algorithm choice. If they give similar results, the choice may be unimportant. Else, if the results differ, further investigation may be needed in order to reveal more about the source of the disparity (Bryson, Dorsett, and Purdon, 2002). We implement eleven matching algorithms, including NN matching without replacement (without caliper and with calipers of 0.01, 0.02 and 0.05) and NN matching with replacement with the same calipers. To see if the estimates differ when more neighbours are included, we additionally implement oversampling with 2,5 and 10 nearest neighbours. ${ }^{20}$

Table 3 contains the results for the main groups for the last month of the observation period. Bold letters indicate significance at the $1 \%$-level, italic letters refer to the $5 \%$-level, standard errors are bootstrapped with 50 replications. The estimates illustrate two points: First of all, the results are not sensitive to the chosen matching algorithm. For men in West Germany the effects are insignificant

\footnotetext{
${ }^{20}$ Matching is implemented using the STATA module PSMATCH2 by Leuven and Sianesi (2003).
} 
and centered around zero. For men in East Germany the significant effects vary between $-2.37 \%$ (5-NN-Matching) and -2.94\% (NN with replacement). This means that the employment rate of men in East Germany, who started their JCS in February 2000, is in December 2002 on average between $2.37 \%$ and $2.94 \%$ lower when compared to matched non-participants. We will give an extensive interpretation of the results in the next section and restrict the discussion here to sensitivity issues. The significant effects for females in East Germany vary between -1.06\% (10 NN) and $-1.93 \%$ (NN with replacement). The only group for whom a somewhat higher variation in the effects is detected are women in West Germany, where the lowest estimated effect is $4.51 \%$ (NN without replacement and without caliper) and the highest estimated effect is $6.1 \%(10 \mathrm{NN})$. The second point to note is that the standard errors are (as expected) in general lower for the oversampling algorithms, even though the differences here are not very pronounced. Hence, the choice of the matching algorithm seems not to be a critical issue in our case. The results show that the estimates are not sensitive to the algorithm choice and that the improvement which comes from oversampling methods in terms of reduced variance is limited only. Therefore, we decide to use NN matching for the further analysis. Since we have a very large sample of non-participants, the probability of finding good matches without using replacement is quite high. To avoid an unnecessary inflation of the variance, we match without replacement. Finally, to ensure a good matching quality, we implement a caliper of 0.02 . This is mostly driven by the finding for women in West Germany, where imposing this caliper reduces the number of treated observations by approximately $4.6 \%$ of the sample. In turn, this means that if we did not impose this caliper, the distance in the propensity scores would be higher than 0.02 for $4.6 \%$. For the other groups, imposing the caliper does not have much influence. Henceforth, we use NN matching without replacement and a caliper of 0.02 for the analysis.

\subsection{Common Support}

Before assessing the matching quality, it is important to check the overlap or common support region for participants and non-participants. The most straightforward way is a visual analysis of the density distribution of the propensity score in both groups. The results can be found in figures A.1 to A.4 in appendix A. The left hand side of each graph shows the propensity score distribution for the non-participants, the right hand side refers to the participants in each group. Taking for instance the results of men in West Germany (figure A.1), it can be seen that the distribution for non-participants is highly skewed to the left in nearly all of the sub-groups. Problems arise, when the distributions in both groups do not overlap. A good example are short-term unemployed men in West Germany, where quite a large amount of observations in the treatment group has a propensity score over 0.5 and nearly none of the comparison individuals can be found in this region.

There are several ways of imposing the common support condition, e.g. by 'minima and maxima comparison' or 'trimming' (see Caliendo (2005) for an overview). We impose the 'minima and maxima condition' and additionally implement NN matching with a caliper of 0.02 . The idea of minimamaxima comparison is to delete all treated observations, whose propensity score is smaller than the minimum and higher than the maximum in the comparison group. Treated individuals who fall 
outside the common support region have to be disregarded and for these individuals the treatment effect cannot be estimated. Bryson, Dorsett, and Purdon (2002) note that if the proportion of lost individuals is small, this poses few problems. However, if the number is too large, there may be concerns whether the estimated effect on the remaining individuals can be viewed as representative.

Tab. 4: Number of Treated Individuals Lost Due to Common Support Requirement ${ }^{1,2}$

\begin{tabular}{|c|c|c|c|c|c|c|}
\hline \multirow{4}{*}{$\begin{array}{l}\text { West Germany } \\
\text { Total }\end{array}$} & \multicolumn{3}{|c|}{ Men } & \multicolumn{3}{|c|}{ Women } \\
\hline & \multirow{2}{*}{\multicolumn{2}{|c|}{$\begin{array}{l}\text { Before After } \\
\text { Matching }\end{array}$}} & \multirow{3}{*}{$\begin{array}{r}\text { Lost } \\
\text { in \% } \\
0.79\end{array}$} & \multirow{2}{*}{\multicolumn{2}{|c|}{$\begin{array}{c}\text { Before After } \\
\text { Matching }\end{array}$}} & \multirow{3}{*}{$\begin{array}{r}\text { Lost } \\
\text { in \% } \\
6.84\end{array}$} \\
\hline & & & & & & \\
\hline & 2140 & 2123 & & 1052 & 980 & \\
\hline \multicolumn{7}{|l|}{ Age (in years) } \\
\hline$<25$ & 458 & 434 & 5.24 & 182 & 162 & 10.99 \\
\hline $25-50$ & 1337 & 1328 & 0.67 & 709 & 663 & 6.49 \\
\hline$>50$ & 345 & 344 & 0.29 & 161 & 150 & 6.83 \\
\hline \multicolumn{7}{|l|}{ Duration of unemployment } \\
\hline$<13$ weeks & 558 & 440 & 21.15 & 237 & 189 & 20.25 \\
\hline $13-52$ weeks & 744 & 720 & 3.23 & 403 & 365 & 9.43 \\
\hline$>52$ weeks & 838 & 835 & 0.36 & 412 & 400 & 2.91 \\
\hline Without professional experience & 273 & 247 & 9.52 & 159 & 128 & 19.50 \\
\hline Without professional training & 1340 & 1296 & 3.28 & 476 & 447 & 6.09 \\
\hline With high degree & 112 & 96 & 14.29 & 146 & 120 & 17.81 \\
\hline Rehabilitation attendant & 111 & 100 & 9.91 & 44 & 35 & 20.45 \\
\hline With placement restrictions & 354 & 326 & 7.91 & 148 & 117 & 20.95 \\
\hline \multirow[t]{3}{*}{ East Germany } & \multicolumn{3}{|c|}{ Men } & \multicolumn{3}{|c|}{ Women } \\
\hline & Before & After & Lost & Before & After & Lost \\
\hline & Match & hing & in $\%$ & Match & ing & in $\%$ \\
\hline Total & 2924 & 2923 & 0.03 & 5035 & 5027 & 0.16 \\
\hline \multicolumn{7}{|l|}{ Age (in years) } \\
\hline$<25$ & 240 & 229 & 4.58 & 148 & 144 & 2.70 \\
\hline $25-50$ & 1571 & 1570 & 0.06 & 3342 & 3335 & 0.21 \\
\hline$>50$ & 1113 & 1074 & 3.50 & 1545 & 1481 & 4.14 \\
\hline \multicolumn{7}{|l|}{ Duration of unemployment } \\
\hline$<13$ weeks & 578 & 467 & 19.20 & 575 & 431 & 25.04 \\
\hline $13-52$ weeks & 1248 & 1230 & 1.44 & 1970 & 1963 & 0.36 \\
\hline$>52$ weeks & 1098 & 1098 & 0.00 & 2490 & 2490 & 0.00 \\
\hline Without professional experience & 293 & 289 & 1.37 & 498 & 489 & 1.81 \\
\hline Without professional training & 837 & 835 & 0.24 & 1121 & 1116 & 0.45 \\
\hline With high degree & 146 & 136 & 6.85 & 191 & 164 & 14.14 \\
\hline Rehabilitation attendant & 218 & 215 & 1.38 & 156 & 148 & 5.13 \\
\hline With placement restrictions & 394 & 371 & 5.84 & 376 & 362 & 3.72 \\
\hline
\end{tabular}

Table 4 contains the number of treated individuals lost in each of the sub-groups. It can be seen that the number of lost individuals is fairly low for three of the main groups. For men in West Germany we lose $0.79 \%$ of the observations, for men $(0.03 \%)$ and women $(0.16 \%)$ in East Germany the proportion is even smaller. However, for women in West Germany we cannot find similar non-participants for around $6.84 \%$ of the treated population and have to discard these individuals. Figure A.2 makes very clear that the overlap between participating and non-participating women in West Germany is fairly limited in the sub-groups, too. As a consequence, we there lose up to $20.95 \%$ of the treated population (for women with placement restrictions). Hence, interpretation of the effects has to be made careful. 
For the other sub-groups the share of lost individuals is acceptable. However, two sub-groups are problematic for both gender and regions. The first are short-term unemployed persons (less than 13 weeks unemployed). For this group we lose $21.15 \%$ of the participating men in West Germany, $19.20 \%$ of men and $25.04 \%$ of women in East Germany. This means that we are not able to find short-term unemployed individuals in the comparison group that have similar propensity scores as the treated individuals. For women in East Germany this gets very clear when looking at figure A.4 for the short-term unemployed. Whereas the density of observations for the non-participants is very low above 0.2 , participants can be found even at scores close to 1 . The second sub-group are individuals with high degree. For this sub-group the share of lost individuals is $6.85 \%(14.14 \%)$ for men (women) in East Germany and 14.29\% (17.81\%) for men (women) in West Germany. Overall, we note that the share of lost individuals is rather small in East Germany, higher for men in West Germany and highest for women in West Germany.

\subsection{Matching Quality}

Matching Quality for the Main Groups Since we do not condition on all covariates but on the propensity score, we have to check the ability of the matching procedure to balance the relevant covariates. One suitable indicator to assess the distance in the marginal distributions of the $X$ variables is the standardised bias (SB) suggested by Rosenbaum and Rubin (1985). For each covariate $X$ it is defined as the difference of the sample means in the treated and (matched) comparison subsamples as a percentage of the square root of the average of the sample variances in both groups. This is a common approach used in many evaluation studies, e.g. by Sianesi (2004). We estimate the absolute bias between the respective participating and non-participating groups before and after matching took place. To abbreviate the documentation, we calculated the means of the SB before and after matching for the four main groups (Table 5) as an unweighted average of all variables (mean standardised bias, MSB). The results for each variable can be found in table A.5 in appendix A. The overall bias before matching lies between $10.9 \%$ for women in East Germany and $15.36 \%$ for women in West Germany. A significant reduction can be achieved for all groups so that the bias after matching is $2.5 \%$ (3.1\%) for men (women) in West Germany and 1.8\% (1.6\%) for men (women) in East Germany. Clearly, this is an enormous reduction and shows that the matching procedure is able to balance the characteristics in the treatment and the matched comparison group. ${ }^{21}$

Additionally Sianesi (2004) suggests to re-estimate the propensity score on the matched sample (i.e. on participants and matched non-participants) and compare the pseudo- $R^{2}$ 's before and after matching. After matching there should be no systematic differences in the distribution of the covariates

\footnotetext{
${ }^{21}$ Looking at the results in more detail (table A.5) also shows that the matching procedure increases the bias for a few variables. These are in particular categorial dummy variables. A good example is the variable 'professional training' of men in West Germany. The bias before matching for the category 'technical school' has been $1.1 \%$ and increases after matching to $2.8 \%$. This increase has to be seen in relation to the high decrease in the other categories of this variable, e.g. the bias for 'industrial training' drops from $31.27 \%$ to $0.52 \%$. Hence, it is of less importance. There are also two non-categorial variables for which the matching increases the bias: the bias of 'age' for women in East Germany is increased from $1.4 \%$ to $2.5 \%$ and the bias for 'rehabilitation attendant' for men in East Germany increases from $0.1 \%$ to $0.8 \%$. Since the bias after matching is still fairly low, this is of minor importance, too.
} 
Tab. 5: Some Quality Indicators

\begin{tabular}{|c|c|c|c|c|}
\hline & \multicolumn{2}{|c|}{ "West Germany } & \multicolumn{2}{|c|}{ East Germany } \\
\hline & Men & Women & Men & Women \\
\hline \multicolumn{5}{|l|}{ Before Matching } \\
\hline Pseudo $R^{2}$ & 0.1389 & 0.1775 & 0.1225 & 0.1144 \\
\hline$F$-Test ${ }^{1}$ & $2,406.8$ & $1,679.4$ & $2,951.3$ & $4,323.3$ \\
\hline Mean of standardised bias ${ }^{2}$ & 14.62 & 16.08 & 12.01 & 10.83 \\
\hline \multicolumn{5}{|l|}{ After Matching } \\
\hline Pseudo- $R^{2}$ & 0.006 & 0.009 & 0.004 & 0.003 \\
\hline$F$-Test ${ }^{1}$ & 38.0 & 23.4 & 35.3 & 39.2 \\
\hline Mean of standardised bias ${ }^{2}$ & 2.51 & 3.20 & 1.78 & 1.60 \\
\hline
\end{tabular}

between both groups. Therefore, the pseudo- $R^{2}$ after matching should be fairly low. As the results from Table 5 show, this is true for our estimation. The results of the $F$-tests (with degrees of freedom in brackets) point in the same direction, indicating a joint significance of all regressors before, but not after matching.

Matching Quality for the Sub-Groups and the Regions Now that we have shown that the matching procedure is able to balance the distribution of the covariates between treated and comparison individuals in the main groups, we have to test this for the sub-groups and the regions, too.

Table 6 contains the results for the eleven sub-groups. The first column in the table refers to the MSB before matching and the second column shows the MSB after matching, when matching is done with the estimated 'overall' propensity score as shown in table A.4. This propensity score specification, which we label $P_{1}$, has been done separately for the four main groups. However, it is very clear that the matching procedure based on the overall scores is not able to balance the covariates between treated and matched non-treated individuals in the sub-groups. For example, the bias after matching for men in West Germany reaches a level of $13.23 \%$ for rehabilitation attendants. Even though this is a reduction compared to the MSB before matching, it is not acceptable. For women in West Germany in this group the bias after matching is $18.69 \%$. In East Germany the bias after matching is not much lower, reaching levels of $13.11 \%$ for young men and $15.11 \%$ for young women. Even though there are some sub-groups for which the bias is acceptable, the overall matching quality in the sub-groups is not. Hence, alternative strategies are called for.

One way to do so is to re-define the propensity score estimation. Whereas the 'overall' propensity score estimation has only been done separately for men and women in West and East Germany, we estimate in a second step 'group-specific' propensity scores. The basic idea behind that is to capture the varying influence of the variables for certain sub-groups more accurately. Since we have eleven sub-groups for both gender and regions, we are left with 44 propensity score estimations. ${ }^{22}$ Based on these 'group-specific' estimations, labelled $P_{2}$, we re-run the matching procedure and estimate

\footnotetext{
${ }^{22}$ The results of these estimations are available on request by the authors.
} 
Tab. 6: Mean Standardised Bias in the Sub-Groups ${ }^{1,2,3}$

\begin{tabular}{|c|c|c|c|c|c|c|c|c|c|c|c|c|}
\hline \multirow[b]{5}{*}{ Propensity Score Specification } & \multicolumn{6}{|c|}{ West Germany } & \multicolumn{6}{|c|}{ East Germany } \\
\hline & \multicolumn{3}{|c|}{ Men } & \multicolumn{3}{|c|}{ Women } & \multicolumn{3}{|c|}{ Men } & \multicolumn{3}{|c|}{ Women } \\
\hline & \multirow{3}{*}{$\begin{array}{c}\text { Before } \\
\text { Match- } \\
\text { ing }\end{array}$} & \multirow{2}{*}{\multicolumn{2}{|c|}{$\begin{array}{l}\text { After } \\
\text { Matching } \\
\text { with }\end{array}$}} & \multirow{3}{*}{$\begin{array}{c}\text { Before } \\
\text { Match- } \\
\text { ing }\end{array}$} & \multirow{2}{*}{\multicolumn{2}{|c|}{$\begin{array}{c}\text { After } \\
\text { Matching } \\
\text { with }\end{array}$}} & \multirow{3}{*}{$\begin{array}{c}\text { Before } \\
\text { Match- } \\
\text { ing }\end{array}$} & \multirow{2}{*}{\multicolumn{2}{|c|}{$\begin{array}{c}\text { After } \\
\text { Matching } \\
\text { with }\end{array}$}} & \multirow{3}{*}{$\begin{array}{c}\text { Before } \\
\text { Match- } \\
\text { ing }\end{array}$} & \multirow{2}{*}{\multicolumn{2}{|c|}{$\begin{array}{c}\text { After } \\
\text { Matching } \\
\text { with }\end{array}$}} \\
\hline & & & & & & & & & & & & \\
\hline & & $P_{1}$ & $P_{2}$ & & $P_{1}$ & $P_{2}$ & & $P_{1}$ & $P_{2}$ & & $P_{1}$ & $P_{2}$ \\
\hline \multicolumn{13}{|l|}{ Sub-Groups } \\
\hline \multicolumn{13}{|l|}{ Age (in years) } \\
\hline$<25$ & 10.48 & 11.53 & 3.08 & 12.50 & 14.37 & 6.82 & 14.74 & 13.11 & 4.94 & 13.73 & 15.11 & 8.90 \\
\hline $25-50$ & 11.30 & 5.82 & 2.66 & 15.56 & 5.79 & 2.98 & 11.91 & 3.98 & 2.47 & 9.84 & 2.48 & 1.36 \\
\hline$>50$ & 17.82 & 12.48 & 5.83 & 20.48 & 12.70 & 6.62 & 16.79 & 9.48 & 2.55 & 14.98 & 6.56 & 1.55 \\
\hline \multicolumn{13}{|l|}{ Duration of unemployment } \\
\hline$<13$ weeks & 15.71 & 9.79 & 4.96 & 16.18 & 12.19 & 4.58 & 19.05 & 10.47 & 4.74 & 13.78 & 10.80 & 4.37 \\
\hline $13-52$ weeks & 12.79 & 5.89 & 4.04 & 16.10 & 7.51 & 4.32 & 12.43 & 3.45 & 2.42 & 11.74 & 4.03 & 1.53 \\
\hline$>52$ weeks & 17.77 & 6.03 & 3.06 & 19.13 & 7.65 & 4.18 & 13.55 & 7.51 & 2.00 & 11.61 & 3.48 & 1.69 \\
\hline Without profession & 14.02 & 9.50 & 5.69 & 15.93 & 11.49 & 6.36 & 12.10 & 10.43 & 4.18 & 12.17 & 5.51 & 3.35 \\
\hline Without professional training & 14.31 & 3.99 & 3.29 & 16.79 & 4.68 & 4.25 & 11.17 & 5.68 & 2.48 & 11.04 & 4.42 & 2.72 \\
\hline With high degree & 17.18 & 10.64 & 7.52 & 14.50 & 9.64 & 5.77 & 18.14 & 12.99 & 6.10 & 15.04 & 12.48 & 5.64 \\
\hline Rehabilitation attendant & 18.13 & 13.23 & 8.45 & 23.96 & 18.69 & 16.31 & 12.88 & 10.05 & 4.38 & 15.87 & 10.71 & 5.87 \\
\hline With placement restrictions & 19.29 & 8.92 & 4.61 & 26.99 & 11.37 & 4.99 & 15.35 & 8.22 & 3.91 & 18.37 & 6.84 & 3.11 \\
\hline
\end{tabular}

Standardised before matching calculated as: $100 \cdot\left(\bar{X}_{1}-\bar{X}_{0}\right) /\left\{\sqrt{\left(V_{1}(X)+V_{0}(X)\right) / 2}\right\}$.

Standardised after matching calculated as: $100 \cdot\left(\bar{X}_{1 M}-\bar{X}_{0 M}\right) /\left\{\sqrt{\left(V_{1 M}(X)+V_{0 M}(X)\right) / 2}\right\}$.

${ }^{1}$ Mean standardised bias has been calculated as an unweighted average of all covariates.

${ }^{2} P_{1}$ refers to the 'overall' propensity score estimation.

${ }^{3} P_{2}$ refers to the 'group-specific' propensity score estimation.

the MSB once again. It can be seen that the MSB is now clearly lower not only compared to the situation before matching but also compared to the situation when matching on the 'overall' score. This result shows that using the 'overall' score specification has not been fine enough to balance the relevant characteristics between participants and non-participants in the sub-groups. Hence, we will use the 'group-specific' propensity scores for the further analysis in the sub-groups.

Finally, looking at the MSB in the different regions (table A.6 in the appendix) shows rather good results. The MSB after matching is between 2.3 and $6.9 \%$ in five out of seven regions. Two exceptions are the clusters IV and V, where the MSB for men after matching is $8.2 \%$ (cluster IV) and $10.0 \%$ (cluster V). For women, the bias after matching is even higher at $12.2 \%$ in cluster IV and $10.6 \%$ in cluster V. However, since these are also the clusters with the lowest number of participants, we refrain from a cluster-specific estimation and use the overall specification of the propensity score for further analysis in the clusters.

\section{Empirical Results}

An important decision which has to be made in every evaluation is when to measure the programme effects. The empirical analysis should ensure that participants and non-participants are compared in the same economic environment and the same lifecycle position. The literature is dominated by two approaches, either comparing individuals from begin or after the end of programmes. The latter approach is problematic for two reasons. First, since it implies comparison of participants and 
non-participants in the month(s) after programmes end, very different economic situations maybe compared if exits are spread over a longer time period. Second, this approach entails an endogeneity problem of programme exits (Gerfin and Lechner, 2002). A second approach which is predominant in the recent literature (see e.g. Sianesi (2004) or Gerfin and Lechner (2002)) and which is also used here, measures the effects from begin of the programmes. By doing so, the policy-relevant question if the placement officer should place an unemployed individual in February 2000 in a JCS or not, can be answered. What should be kept in mind is the possible occurrence of locking-in effects for the group of participants. van Ours (2004) notes that the net effect of a programme consists of two opposite effects: First, the employment probability of the participants is expected to rise due to positive aspects of the programme. Second, since participants who are involved in the programmes do not have the same time to look for new jobs as non-participants, a reduced search intensity during programmes is expected. Since it is not possible to disentangle both effects, locking-in effects should be seen as a constituent part of the overall programme effect (Sianesi, 2001). When interpreting the results the different impacts of the two underlying effects have to be considered. As to the fall in the search intensity, we should expect an initial negative locking-in effect from any kind of participation in a programme. To assess the possible magnitude of this initial effect it is helpful to look at the programme exit rates in each group. ${ }^{23}$ Most of the participants leave the programmes after one year. In March 2001, around 80\% (74\%) of the male (female) participants in West Germany have left the programmes. The corresponding numbers are approximately $91 \%$ for men and $92 \%$ for women in East Germany. ${ }^{24}$ Since we observe the outcome of the individuals until almost three years after programmes start, successful programmes should overcompensate for this initial fall.

Results for the Main Groups The results from the begin (February 2000) to the end (December 2002) of our observation period for the main and the sub-groups are depicted in figures 1 to 4 . Figure 1 contains the results for men in West Germany. The solid line in the graphs describes the monthly employment effect, i.e. the difference in the employment rates between participants and matched nonparticipants. The graphs for the main group are captioned 'total' in the figures. All of the graphs have one thing in common, namely a large drop in the effects for the first months after programme start. This can be interpreted as the expected locking-in effect, which is more pronounced for men (figure 1) and women (figure 2) in West Germany than for men (figure 3) and women (figure 4) in East Germany. To allow a more accurate discussion, we have also put together the results for six selected months in tables A.7 for West Germany and A.8 for East Germany in the appendix. Five months after programmes have started (in July 2000), the effects for men in West Germany lie around $-21.1 \%$. That means that the average employment rate of participating men is about $21 \%$ lower in comparison to matched non-participants. Clearly, this strong reduction is expected as nearly

\footnotetext{
${ }^{23}$ Tables with the cumulated exit rates for the main and the sub-groups are available on request by the authors.

${ }^{24}$ At first sight, this is at odds with our findings in the descriptive analysis, that the programme duration is on average shorter in West Germany. However, the results get clear when looking at the exit rates in the first month, where much more participants leave the programmes in West Germany. Additionally, there is quite a significant variation in the exit rates for the sub-groups, e.g. only $73 \%$ of the male participants who are older than 50 years have left the programme in March 2001. This variation has to be taken into account when interpreting the results.
} 
all participants are still in the programmes, whereas the non-participants have the chance to search, apply for and find a new job. For the interpretation one has to bear in mind, that although JCS are some kind of employment, they are classified as failures when assessing the re-integration success into regular (unsubsidised) employment. For women in West Germany the result is very similar in that month and amounts to around $-20.4 \%$. The situation in East Germany is somewhat different. The effects are here $-14.0 \%$ for men and $-9.4 \%$ for women. Compared to the results for West Germany, this reflects the worse labour market situation with fewer employment opportunities. Being locked into the programme does not have as much influence, since the chances of non-participants to find a new job are lower anyway.

The development of the effects is quite different for both regions, too. Whereas in West Germany a relatively steep increase in the employment effects can be found, the development in East Germany is much smoother. For example, in July 2001 the employment effect has risen to $-12.5 \%$ for men and $11.9 \%$ for women in West Germany. Hence, the negative effects are nearly halved. In East Germany, however, the effects lie around $-10.9 \%$ for men and $-7.5 \%$ for women. Looking at the last month of our observation period (December 2002), we do not find a significant programme effect for men in West Germany. That is, the employment chances of participants and matched non-participants do not differ. However, for women in West Germany we find a significant positive effect of $4.6 \%$, which means that participating women have benefited from the programme in terms of employment chances. However, this positive result has to be treated with caution since women in West Germany have been the smallest group, we have lost a considerable share of participants due to the common support requirement and the estimates imply a confidence interval which is close to zero.

For East Germany on the other hand, we find negative employment effects of $-2.9 \%$ for men and $-1.4 \%$ for women. This shows that the overall effect of JCS for the participating individuals is dissatisfying. Only for one of the groups, namely women in West Germany, we find a positive employment effect nearly three years after programmes have started, whereas for the other three main groups the effects are negative or insignificant. It seems that the pronounced initial negative (locking-in) effect cannot be overcome during our observation period. Judging by these numbers, JCS have to be rated as unsuccessful regarding their goal to re-integrate individuals into regular (unsubsidised) employment.

Results for the Selected Sub-Groups Even though JCS do not work for the participants as a whole, they may work for sub-groups. For instance, one could assume that they are especially effective for the explicit target groups of JCS, like long-term unemployed persons or persons without work experience. Figures 1 to 4 and tables A.7 and A.8 contain the results for our selected subgroups. To abbreviate the discussion, we concentrate on two main points. First, we will examine the occurrence of locking-in effects and second, we will discuss the results at the end of the observation period (December 2002).

Considering locking-in effects is explicitly of interest, since it can be expected that these effects differ for the sub-groups. Good examples are provided by the groups defined by age and unemployment duration. Older unemployed persons have in general fewer labour market opportunities than middle- 


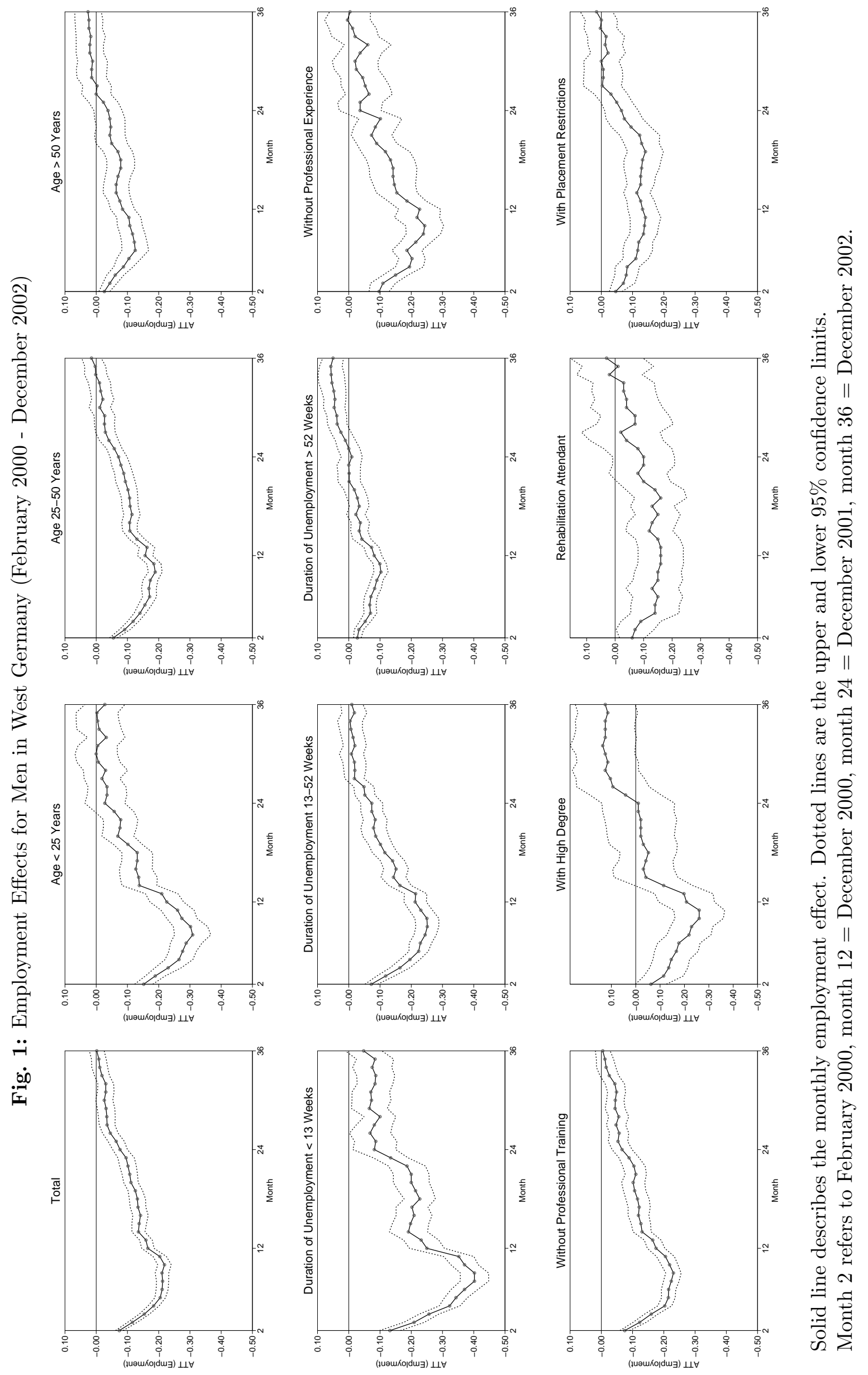




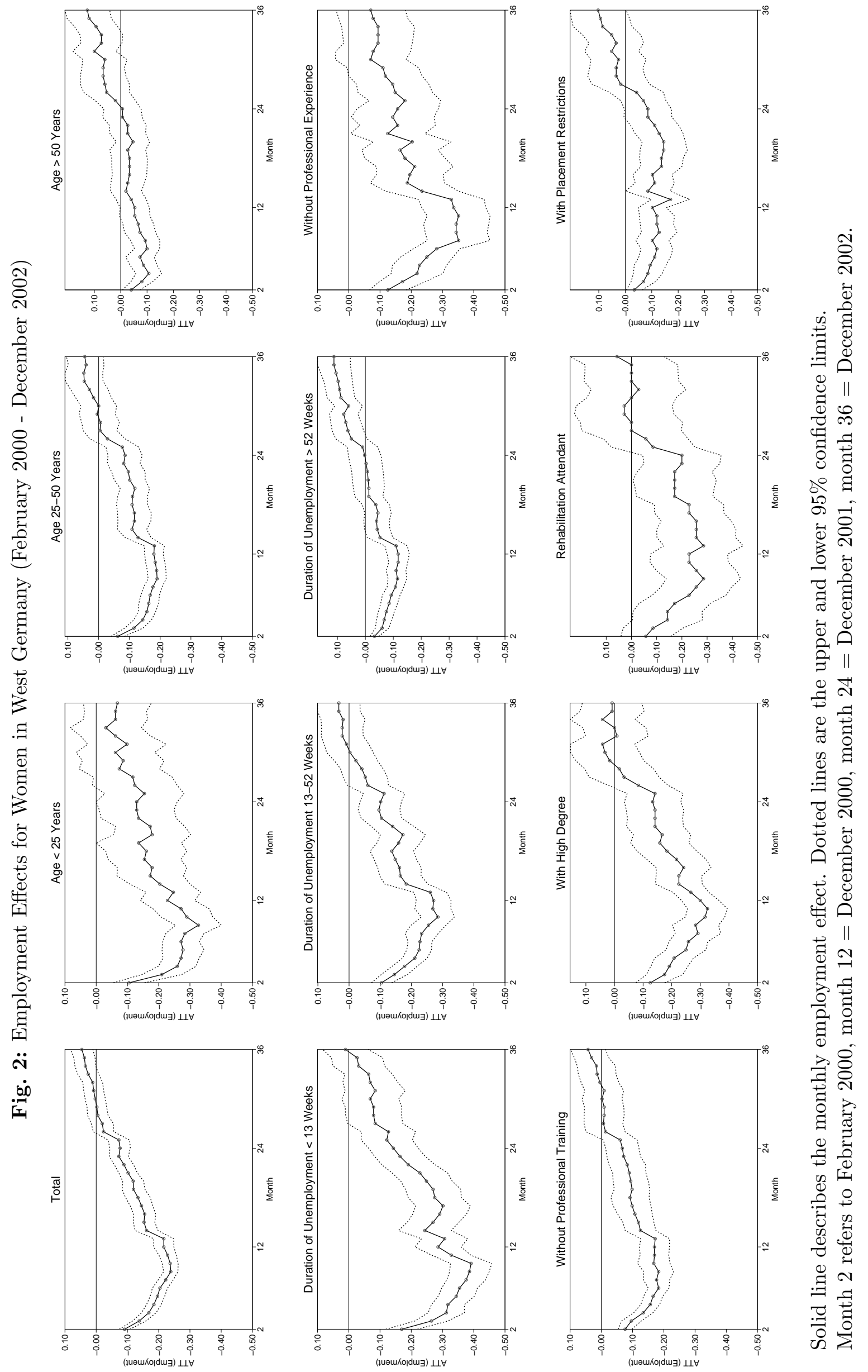




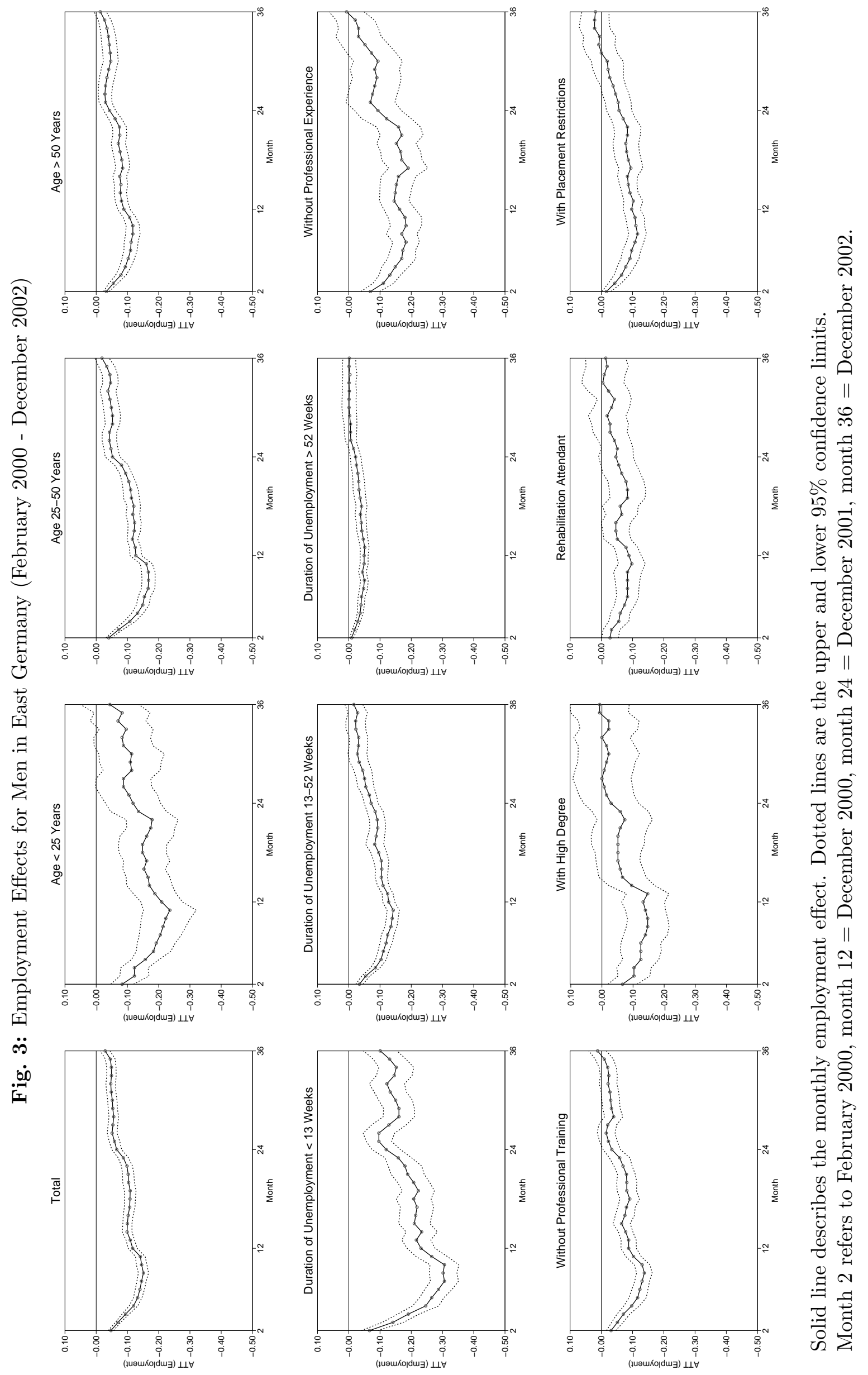




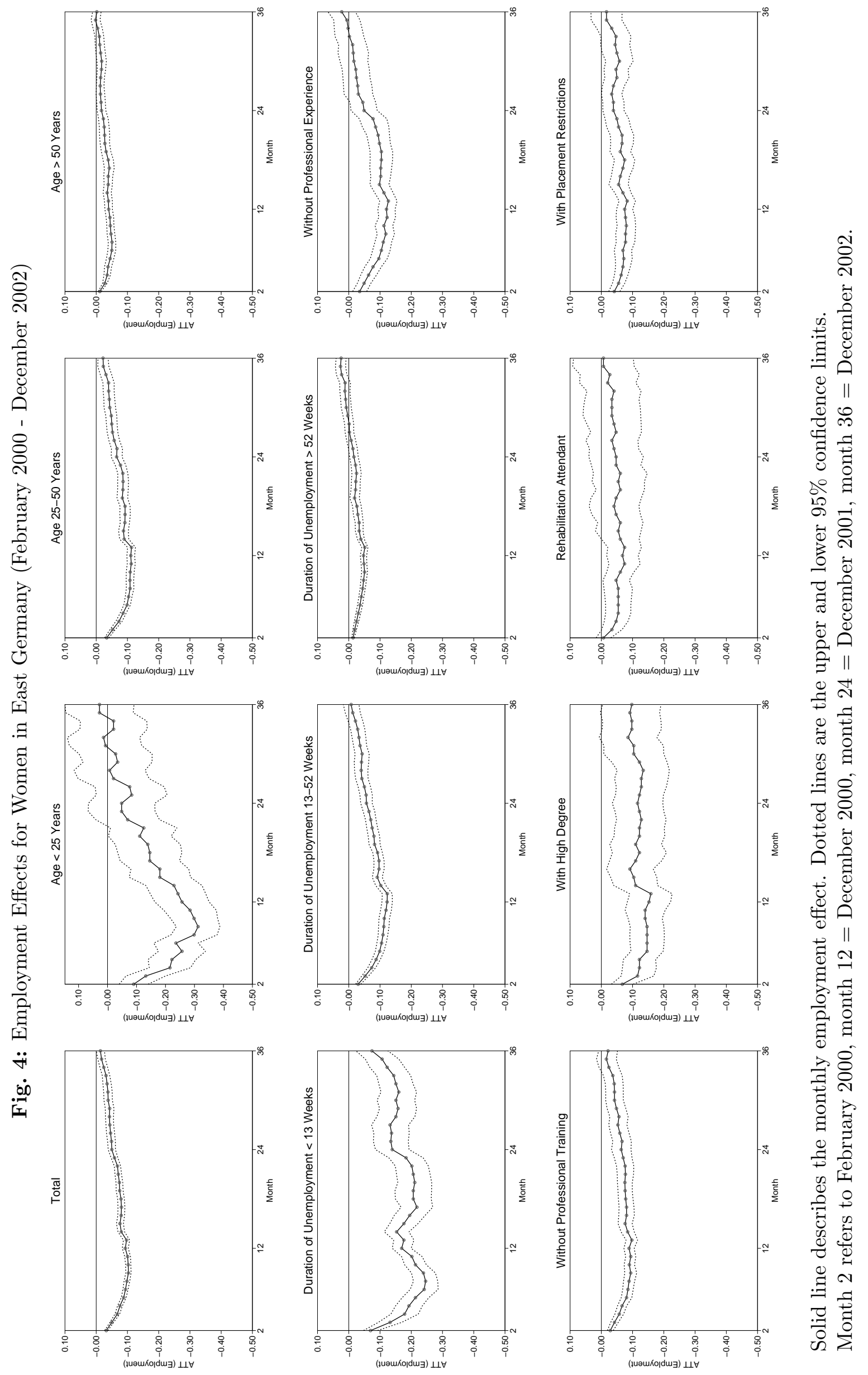


aged or younger persons. Due to the worse 'outside options' of the non-participants, we expect to find weaker locking-in effects for older participants and stronger effects for the other groups (young and middle-aged persons). The figures support these expectations empirically, independently of gender of region. With regard to the previous unemployment duration, it can be assumed that re-integration into the labour market is generally easier for persons with only a short duration of unemployment ('negative duration dependence'). Therefore, short-term unemployed non-participants are expected to have a higher probability of receiving a job offer and hence the locking-in effects are larger. The findings support this expectation.

For the other sub-groups the graphs present a similar picture. We find the initial fall of the employment effects in the first months after programmes have started and rising tendencies after the majority of participants has left the programmes. The reasons have been discussed already.

The second point we want to discuss are the effects for these sub-groups at the end of our observation period (December 2002). For most of the groups we do not find significant programme effects at this point in time, i.e. the employment rates of participants and matched non-participants do not differ nearly three years after programmes have started. That implies that programmes have neither improved nor worsened the employment chances of participating individuals. However, for some of the groups we find significant differences in the employment rates. Long-term unemployed (more than 52 weeks) men $(5.0 \%)$ and women $(11.3 \%)$ in West Germany benefit from participation. These results indicate that JCS could improve the employment chances of this target group. Additionally, high qualified men in West Germany benefit from participation (12.5\%), whereas for low qualified persons and individuals without work experience no significant effects can be established. This is intuitively not understandable, since programmes should be designed for persons who are most in need of assistance. Another group who benefits from participation are older women in West Germany, whose employment rate is $12.7 \%$ higher than for matched non-participants. This is an encouraging result, because older unemployed persons in particular have only poor opportunities to return to the first labour market. Although for most groups we do not find any enhancement of the employment chances after participation, the results indicate a tendency that programmes are actually only useful for the most-disadvantaged in terms of unemployment duration and age.

Considering the results for the sub-groups in East Germany reveals a somewhat different picture. Focussing on the male groups, we only find a significant negative effect $(-10.1 \%)$ for participants with a short unemployment duration before programme. What has to be kept in mind, is the relatively high share of individuals in this group which we have lost due to the common support restriction. Hence, we are reluctant to overemphasise the relevance of this effect. For all other groups no significant differences in the employment rates can be established. For women in East Germany the results are disappointing as well. Middle-aged $(-2.2 \%)$ as well as short-term unemployed women (-7.4\%) suffer from participation. Another group with clearly negative programme effects in December 2002 are high qualified women (-9.8\%). However, there is also one group (long-term unemployed women) for whom we find a small $(2.5 \%)$ positive programme effect. For the other groups no significant differences can be established. Thus, the above stated hypothesis that programmes are actually only 
Tab. 7: Employment Effects in the Regional Clusters

\begin{tabular}{|c|c|c|c|c|c|c|c|c|c|c|c|c|}
\hline & \multicolumn{2}{|c|}{ Jul 00} & \multicolumn{2}{|c|}{ Dec 00} & \multicolumn{2}{|c|}{ Jul 01} & \multicolumn{2}{|c|}{ Dec 01} & \multicolumn{2}{|c|}{ Jul 02} & \multicolumn{2}{|c|}{ Dec 02} \\
\hline & Effect & S.E. & Effect & S.E. & Effect & S.E. & Effect & S.E. & Effect & S.E. & Effect & S.E. \\
\hline \multicolumn{13}{|l|}{ Men } \\
\hline Cluster Ia & -0.1484 & 0.0118 & .1095 & 0.0113 & -0.0980 & 0.0158 & -0.0663 & 0.0148 & -0.0346 & 0.0186 & -0.0014 & 0.0187 \\
\hline Cluster Ib & -0.1477 & 0.0074 & -0.1245 & 0.0080 & -0.1080 & 0.0077 & -0.0656 & 0.0086 & -0.0518 & 0.0088 & -0.0298 & 0.0106 \\
\hline Cluster Ic & -0.1957 & 0.0220 & -0.1615 & 0.0245 & -0.1677 & 0.0255 & -0.1025 & 0.0236 & -0.0652 & 0.0293 & -0.0124 & 0.0298 \\
\hline Cluster II & -0.1446 & 0.0126 & -0.1557 & 0.0141 & -0.0723 & 0.0169 & -0.0623 & 0.0176 & -0.0145 & 0.0172 & -0.0033 & 0.0175 \\
\hline Cluster III & -0.2340 & 0.0137 & -0.1711 & 0.0192 & -0.1220 & 0.0231 & -0.0818 & 0.0210 & -0.0377 & 0.0233 & -0.0063 & 0.0239 \\
\hline Cluster IV & -0.1646 & 0.0381 & -0.0732 & 0.0405 & -0.0732 & 0.0552 & -0.0427 & 0.0486 & 0.0000 & 0.0529 & 0.0183 & 0.0472 \\
\hline Cluster V & -0.3311 & 0.0312 & -0.2669 & 0.0315 & -0.2264 & 0.0339 & -0.1284 & 0.0403 & -0.0912 & 0.0363 & -0.0507 & 0.0331 \\
\hline \multicolumn{13}{|l|}{ Women } \\
\hline Cluster Ia & -0.0815 & 0.0075 & -0.0783 & 0.0091 & -0.0618 & 0.0114 & -0.0511 & 0.0105 & -0.0404 & 0.0157 & -0.0189 & 0.0149 \\
\hline Cluster Ib & -0.0990 & 0.0059 & -0.0940 & 0.0046 & -0.0788 & 0.0054 & -0.0537 & 0.0058 & -0.0456 & 0.0072 & -0.0155 & 0.0067 \\
\hline Cluster Ic & -0.1043 & 0.0141 & -0.1329 & 0.0171 & -0.0818 & 0.0212 & -0.0573 & 0.0214 & -0.0593 & 0.0200 & -0.0450 & 0.0224 \\
\hline Cluster II & -0.1647 & 0.0214 & -0.1909 & 0.0185 & -0.1265 & 0.0268 & -0.1146 & 0.0293 & -0.0358 & 0.0346 & -0.0191 & 0.0292 \\
\hline Cluster III & -0.1935 & 0.0212 & -0.2016 & 0.0231 & -0.1210 & 0.0272 & -0.0565 & 0.0299 & 0.0215 & 0.0301 & 0.0618 & 0.0326 \\
\hline Cluster IV & -0.1972 & 0.0639 & -0.1972 & 0.0627 & -0.0423 & 0.0817 & -0.0845 & 0.0875 & 0.1127 & 0.0943 & 0.1268 & 0.0882 \\
\hline Cluster V & -0.3077 & 0.0376 & -0.2582 & 0.0387 & -0.1648 & 0.0459 & -0.0769 & 0.0505 & -0.0055 & 0.0478 & 0.0000 & 0.0470 \\
\hline
\end{tabular}

Bold letters indicate significance on a $1 \%$ level, italic letters refer to the $5 \%$ level, standard errors are bootstrapped with 50 replications.

Results refer to NN matching without replacement and a caliper of 0.02 .

likely to work for the legally defined target groups, can only be supported for long-term unemployed women.

Results for the Regional Clusters We use the FEA clusters to analyse possible effect heterogeneity that may occur due to differences in the regional labour market environment. Two hypotheses may be formulated: First, it may be the case that JCS work in situations with high labour market imbalances. Second, it may also be stated that JCS work better in prospering regions (when concentrating more explicitly on specific target groups). To check these hypotheses, we estimate the effects for the seven clusters. Table 7 contains the employment effects for men and women in these clusters in six selected months. To abbreviate the discussion, we concentrate on the locking-in effect (July 2000) and the effects at the end of our observation period (December 2002). Starting with men in East Germany, it can be seen that the highest locking-in effect is measured in districts of cluster Ic $(-19.6 \%)$, which have the relatively best labour market conditions. For women a similar picture emerges, even though less pronounced (-10.4\% in Ic). The same story extends to West Germany, where men (women) in districts of cluster $\mathrm{V}$ have an average employment effect of $-33.1 \%(-30.7 \%)$ in July 2000. One might speculate that this is caused by the better 'outside options' of non-participants in these clusters. Thus, participants in clusters with a better labour market environment (Ic and V) experience lower locking-in effects.

Turning to the results in December 2002 does not allow to extend these findings. Most of the results are insignificant and we do not find that programme participants in clusters with better labour market situations are worse off. In total, we can establish significant differences in the employment levels of participants and matched non-participants for only three groups. The first group are men 
in districts of cluster Ib, the 'typical' East German labour office. There we find a negative effect of $-3.0 \%$. For women in cluster Ib $(-1.6 \%)$ and Ic $(-4.5 \%)$ the effects are significantly negative, too. It should be noted that the results do not diverge much from the overall results in West and East Germany. Based on these findings, neither of the two stated hypotheses can be confirmed.

Sensitivity of the Results to Unobserved Heterogeneity The estimation of treatment effects with matching estimators is based on the CIA. Hence, if both groups differ on unobserved variables which simultaneously affect assignment into treatment and the outcome variable, there may be a 'hidden bias'. It should be clear that matching estimators are not robust against this 'hidden bias'. Since it is impossible to estimate the magnitude of selection bias with non-experimental data, we address this problem with the bounding approach proposed by Rosenbaum (2002). The basic question to be answered is, if inference about programme effects may be altered by unobserved factors. In other words, we want to determine how strongly an unmeasured variable must influence the selection process in order to undermine the implications of matching analysis. Recent applications of this approach can be found in Aakvik (2001), DiPrete and Gangl (2004) and Hujer, Caliendo, and Thomsen (2004).

We outline this approach briefly, an extensive discussion can be found in Rosenbaum (2002). The participation probability for individual $i$ with observed characteristics $x_{i}$ can be written as $P\left(x_{i}\right)=$ $P\left(D_{i}=1 \mid x_{i}\right)=F\left(\beta x_{i}+\gamma u_{i}\right)$, where $u_{i}$ is the unobserved variable and $\gamma$ is the effect of $u_{i}$ on the participation decision. Clearly, if there is no hidden bias, $\gamma$ will be zero and the participation probability will solely be determined by $x_{i}$. However, if hidden bias exists, two individuals with the same observed covariates $x$ have differing chances of receiving treatment. Following Aakvik (2001), we assume for the sake of simplicity that the unobserved covariate is a dummy variable with $u_{i} \in\{0,1\}$. A good example is the case, where motivation of the individuals is an important determinant of participation and the outcome variable, and a person is either motivated $(u=1)$ or not $(u=0)$. Rosenbaum (2002) derives the following bounds on the log-odds ratio that either of the two matched individuals will receive treatment:

$$
\frac{1}{e^{\gamma}} \leq \frac{P\left(x_{i}\right)\left(1-P\left(x_{j}\right)\right)}{P\left(x_{j}\right)\left(1-P\left(x_{i}\right)\right)} \leq e^{\gamma}
$$

Matched individuals have the same probability of participating only if $e^{\gamma}=1$. Else, if for example $e^{\gamma}=2$, individuals who appear to be similar (in terms of $x$ ) may differ in their odds of receiving the treatment by as much as a factor of 2 . In this sense, $e^{\gamma}$ is a measure of the degree of departure from an estimation that is free of hidden bias (Rosenbaum, 2002). The basic idea now is to increase the influence of $e^{\gamma}$ and see if inference from the test statistic is changed. Aakvik (2001) suggests to use the Mantel and Haenszel (1959) test statistic, which compares the successful number of persons in the treatment group against the same expected number, given the treatment effect is zero.

Table A.9 in appendix A contains the results of the sensitivity analysis for two selected months (July and December 2002) of the examined sub-groups. First of all, the table contains the effects and the results of the Mantel and Haensel (1959) test-statistic for the situation free of hidden bias $\left(e^{\gamma}=1\right)$. A 
$\chi^{2}$-value below 3.84 indicates that the treatment effect is insignificant. Clearly, a sensitivity analysis for insignificant effects is not meaningful and hence will be omitted. For the significant effects, we gradually increase the level of $e^{\gamma}$ until the inference about the treatment effect is changed. In other words, we are assessing the strength unmeasured influences would require in order to change inference about the treatment effect.

The interpretation is straightforward: Taking the effect for men in West Germany in July 2002 as an example, we see that the effect is $-3.06 \%$ and significant. The critical value of $e^{\gamma}$ is between 1.50 and 1.55. A critical value of 1.50 suggests that individuals with the same $X$-vector differ in their odds of participation by a factor of 1.50 , or $50 \%$. It is important to note that these are worst-case scenarios. Hence, a critical value of $e^{\gamma}=1.50$ does not mean that unobserved heterogeneity exists and that there is no effect of treatment on the outcome variable. This result only states that the confidence interval for the effect would include zero if an unobserved variable caused the odds ratio of treatment assignment to differ between treatment and comparison groups by 1.50. Additionally, this variable's effect on the outcome would have to be so strong that it almost perfectly determines the outcome in each pair of matched cases in the data. However, even if there is unobserved heterogeneity to a degree of $e^{\gamma}=1.50$ in the group of West German men, inference about the treatment effect would not be changed.

The results are ambivalent and differ between West and East Germany. In West Germany most of the effects for men and women in the sub-groups are insignificant. But for those groups where the effects are significant, even a large influence of unobserved heterogeneity does not have much influence on the inference about treatment effects. The lowest critical value of $e^{\gamma}$ can be found for men without professional training in July 2002 (1.40-1.45) and the largest critical values of 1.75-1.80 can be found for high-qualified men (in July and December 2002) as well as for long-term unemployed women in July 2002 and high qualified women in December 2002. Therefore, we can conclude for West Germany that even large amounts of unobserved heterogeneity would not alter the inference about the estimated effects.

In contrast to that the results in East Germany are not so clear-cut. We find that for some of the subgroups, like older or short-term unemployed men as well as for high qualified women and for women with placement restrictions, inference would change in July 2002 even with small amounts of hidden bias. The critical value of $e^{\gamma}$ is somewhere below 1.05, which implies that even small magnitudes of 'hidden bias' would alter the inference. Consequently, interpretation for these sub-populations hinges on this restriction. For the results of the main groups, i.e. men and women, the critical value of $e^{\gamma}$ in December 2002 is somewhere between 1.25 and 1.30. So these effects can be viewed as relatively robust to unobserved heterogeneity.

\section{Conclusion}

The aim of this paper is the evaluation of the re-integration effects of JCS into regular (unsubsidised) employment for the participating individuals in Germany. JCS have been the second most important 
ALMP programme in recent years and provide subsidised jobs for unemployed workers who cannot be integrated into regular employment and do not fulfill the requirements for other programmes. Our analysis is based on a dataset from administrative sources of the FEA which contains information of all participants $(11,151)$, who started a JCS in February 2000. The comparison group consists of job-seekers $(219,622)$ who were eligible for participation in January 2000 but did not participate. Special attention is given to the possible occurrence of individual, i.e. group-specific, and regional effect heterogeneity. That is we estimate the effects separately for men and women in West and East Germany ('main groups') as well as for eleven 'sub-groups' and within seven regional clusters.

Due to the non-experimental data used in this analysis the problem of selection bias has to be addressed. Given the very informative dataset, we apply a matching estimator based on the conditional independence assumption. Since the large number of relevant covariates makes exact matching unfeasible, we use propensity score matching (PSM) for the analysis. When implementing PSM estimators, several decisions have to be made. The estimation of the propensity score is a first and crucial issue and hence we test several alternative specifications. Furthermore, we also test the sensitivity of the effects with respect to different matching algorithms. It becomes apparent that the results are not sensitive to the algorithm choice. The major goal of PSM is to balance the distribution of covariates across the groups of participants and non-participants. A suitable measure to test this is the standardised bias. It turns out that our 'overall' propensity score, which we estimate for the 'main groups', is able to balance the distribution in the 'main groups' very well. However, it is not able to balance the distribution accurately in the sub-groups. Thus, we estimate 'group-specific' propensity scores and use these for the analysis in the sub-groups.

The effects are estimated from begin of the programmes in February 2000 until December 2002. Since JCS are usually supported for twelve months, we find large locking-in effects for all of the groups. The locking-in effects are more pronounced in West Germany and less substantial in East Germany, which may be caused by the better employment opportunities for non-participants in the West.

Regarding the effects for the main groups at the end of the observation period, we find a significant positive effect only for women in West Germany (4.6\%), whereas the effect for men in West Germany is insignificant. For men $(-2.9 \%)$ and women $(-1.4 \%)$ in East Germany the effects are significantly negative. Interpretation of the results may be hampered by two issues. First, the number of treated individuals lost due to the common support requirement and second, the matching quality. As already said, the matching quality is very good for the 'main groups' even though for women in West Germany the matching quality was less satisfying. This group was also the one for whom we lost the highest number of individuals in comparison to the other groups due to the common support requirement, advising some caution when interpreting the effects. Hence, except for women in West Germany, it seems that the initial negative locking-in effect cannot be overcome during the observation period.

For most of the sub-groups we do not find significant effects at all. However, some exceptions have to be noted. Long-term unemployed men (5.0\%) and women $(12.7 \%)$ as well as high qualified men $(12.5 \%)$ and older women $(12.7 \%)$ in West Germany benefit from participation. Common support 
and matching quality are not an issue for the long-term unemployed, but they definitely are for the latter two groups, since we lose nearly $7 \%$ of older women and over $14 \%$ of high qualified men due to failing common support. Looking additionally at the relatively high remaining bias after matching for these two groups makes an interpretation of their results questionable.

The only sub-group with a positive effect in East Germany are long-term unemployed women (2.5\%). In East Germany we find significant negative effects for short-term unemployed men $(-10.1 \%)$ and women $(-7.4 \%)$ as well as for women between 25 and 50 years $(-2.2 \%)$ and for high qualified women $(-9.8 \%)$. Matching quality is satisfying for all of these five sub-groups. However, for the short-term unemployed persons and women with high degree we lose substantial amounts of individuals due to failure of the common support, indicating that it is problematic to find short-term unemployed who did not participate and have similar characteristics.

The positive findings for the long-term unemployed persons may indicate that JCS do work for this problem group of the labour market. However, this result cannot be extended to other problem groups, like individuals with placement restrictions, individuals without work experience or low qualified persons. Even though we would have expected positive effects for these problem groups of the labour market, we did not find any. Our regional analysis did not support any of the hypotheses that the programmes work better either in regions with a depressed or prospering labour market situation. The results for the clusters did not diverge much from the overall result in West and East Germany. To some extent the effects reflect the different purpose of JCS in both parts. Whereas they are used as a relief of the labour market in East Germany they are more tightly addressed to problem groups in the West.

The overall picture is rather disappointing since most of the effects are insignificant or negative. Participation in programmes does not help individuals to re-integrate into regular (unsubsidised) employment. One notable exception are long-term unemployed men and women in West Germany as well as long-term unemployed women in East Germany. The long-term unemployed are usually one of the most problematic groups on the labour market and re-integrating them into regular employment is extremely difficult. Hence, the positive result for them is promising and shows that JCS might work for this target group and might be an alternative for hard-to-place individuals. Clearly, one policy implication is to address programmes to this problem group more tightly, which is at the moment, especially in East Germany, not the case. Limiting access to these programmes and tailoring them more for the ones who need them most might be a way to improve their overall efficiency and offering a 'last chance' for hard-to-place individuals. 


\section{References}

AAKviK, A. (2001): "Bounding a Matching Estimator: The Case of a Norwegian Training Program," Oxford Bulletin of Economics and Statistics, 63(1), 115-143.

Angrist, J. D., And A. B. Krueger (1999): "Empirical Strategies in Labor Economics," in Handbook of Labor Economics, ed. by O. Ashenfelter, and D. Card, pp. 1277-1366. Elsevier Science B.V.

Augurzky, B., And C. Schmidt (2000): "The Propensity Score: A Means to An End," Working Paper, University of Heidelberg.

Blien, U., F. Hirschenauer, M. Arendt, H. J. Braun, D.-M. Gunst, S. Kilcioglu, H. Kleinschmidt, M. Musati, H. Ross, D. Vollkommer, and J. Wein (2004): "Typisierung von Bezirken der Agenturen der Arbeit," Zeitschrift für Arbeitsmarktforschung, 37(2), 146-175.

Blundell, R., and M. Costa-Dias (2002): "Alternative Approaches to Evaluation in Empirical Microeconomics," Portuguese Economic Journal, 1, 91-115.

Breiman, L., J. Friedman, R. Olsen, and C. Stone (1984): Classification and Regression Trees. Wadsworth International Group, Belmont.

Bryson, A., R. Dorsett, and S. Purdon (2002): "The Use of Propensity Score Matching in the Evaluation of Labour Market Policies," Working Paper No. 4, Department for Work and Pensions.

Bundesministerium für Wirtschaft und Arbeit (2003): "Moderne Dienstleistungen am Arbeitsmarkt," http://www.bmwa.bund.de/Navigation/Arbeit/Arbeitsmarktpolitik/moderne-dienstleistungenam-arbeitsmarkt,did=10144.html.

Caliendo, M. (2005): "Microeconometric Evaluation of Labour Market Policies," Unpublished manuscript, J.W.Goethe University of Frankfurt.

Caliendo, M., R. Hujer, and S. Thomsen (2004a): "Identifying Effect Heterogeneity to Improve the Efficiency of Job Creation Schemes in Germany," Working Paper, J.W.Goethe University of Frankfurt.

(2004b): "Individual Employment Effects of Job Creation Schemes in Germany with Respect to Sectoral Heterogeneity," Working Paper, J.W.Goethe University of Frankfurt.

DAwID, A. (1979): "Conditional Independence in Statistical Theory," Journal of the Royal Statistical Society, Series B, 41, 1-31.

DiPrete, T., and M. Gangl (2004): "Assessing Bias in the Estimation of Causal Effects: Rosenbaum Bounds on Matching Estimators and Instrumental Variables Estimation with Imperfect Instruments," Working Paper, WZB. 
FisheR, R. (1935): Design of Experiments. Hafner, New York.

Gerfin, M., And M. Lechner (2002): "A Microeconometroc Evaluation of the active Labour Market Policy in Switzerland," The Economic Journal, 112, 854-893.

Heckman, J., H. Ichimura, J. Smith, and P. Todd (1998): "Characterizing Selection Bias Using Experimental Data," Econometrica, 66, 1017-1098.

Heckman, J., H. Ichimura, and P. Todd (1997): "Matching as an Econometric Evaluation Estimator: Evidence from Evaluating a Job Training Programme," Review of Economic Studies, 64, 605-654.

Heckman, J., R. LaLonde, and J. Smith (1999): "The Economics and Econometrics of Active Labor Market Programs," in Handbook of Labor Economics Vol.III, ed. by O. Ashenfelter, and D. Card, pp. 1865-2097. Elsevier, Amsterdam.

Heckman, J., And J. Smith (1999): "The Pre-Program Earnings Dip and the Determinants of Participation in a Social Program: Implications for Simple Program Evaluation Strategies," Working Paper No. 6983, National Bureau of Economic Research.

Hujer, R., M. Caliendo, and S. Thomsen (2004): "New Evidence on the Effects of Job Creation Schemes in Germany - A Matching Approach with Threefold Heterogeneity," Research in Economics, 58(4), 257-302.

Imbens, G. (2004): "Nonparametric Estimation of Average Treatment Effects under Exogeneity: A Review," The Review of Economics and Statistics, 86(1), 4-29.

Leuven, E., and B. Sianesi (2003): "PSMATCH2: Stata Module to Perform Full Mahalanobis and Propensity Score Matching, Common Support Graphing, and Covariate Imbalance Testing," Software, http://ideas.repec.org/c/boc/bocode/s432001.html.

Mantel, N., And W. Haenszel (1959): "Statistical Aspects of the Analysis of Data from Retrospective Studies of Disease," Journal of the National Cancer Institute, 22, 719-748.

Neyman, J. (1935): "Statistical Problems in Agricultural Experiments," The Journal of the Royal Statistical Society, 2, 107-180.

Puhani, P. (1998): "Advantage through Training? A Microeconometric Evaluation of the Employment Effects of Active Labour Market Programmes in Poland," Discussion Paper No. 98-25, ZEW.

Quandt, R. (1972): "Methods for Estimating Switching Regressions," Journal of the American Statistical Association, 67(338), 306-310.

(1988): The Economics of Disequilibrium. Basil Blackwell, Oxford. 
Rosenbaum, P., and D. Rubin (1983): "The Central Role of the Propensity Score in Observational Studies for Causal Effects," Biometrika, 70, 41-50.

— (1985): "Constructing a Control Group Using Multivariate Matched Sampling Methods that Incorporate the Propensity Score," The American Statistican, 39, 33-38.

Rosenbaum, P. R. (2002): Observational Studies. Springer, New York.

Roy, A. (1951): "Some Thoughts on the Distribution of Earnings," Oxford Economic Papers, 3, $135-145$.

Rubin, D. (1974): "Estimating Causal Effects to Treatments in Randomised and Nonrandomised Studies," Journal of Educational Psychology, 66, 688-701.

Rubin, D. B., and N. Thomas (1996): "Matching Using Estimated Propensity Scores: Relating Theory to Practice," Biometrics, 52, 249-264.

SiANESI, B. (2001): "Differential effects of Swedish active labour market programmes for unemployed adults during the 1990s," Working Paper No. 01/25, The Institute for Fiscal Studies. (2004): "An Evaluation of the Active Labour Market Programmes in Sweden," The Review of Economics and Statistics, 86(1), 133-155.

Smith, H. (1997): "Matching with Multiple Controls to Estimate Treatment Effects in Observational Studies," Sociological Methodology, 27, 325-353.

Smith, J. (2000): "A Critical Survey of Empirical Methods for Evaluating Active Labor Market Policies," Schweizerische Zeitschrift für Volkswirtschaft und Statistik, 136(3), 1-22.

Smith, J., And P. Todd (2005): "Does Matching Overcome LaLonde's Critique of Nonexperimental Estimators?," Journal of Econometrics, 125(1-2), 305-353.

van Ours, J. (2004): "The Locking-in Effect of Subsidized Jobs," Journal of Comparative Economics, 32(1), 37-52. 


\section{A Tables and Figures}

Tab. A.1: Selected Descriptives for the Main Groups

\begin{tabular}{|c|c|c|c|c|c|c|c|c|}
\hline \multirow[b]{3}{*}{ Variable } & \multicolumn{4}{|c|}{ West } & \multicolumn{4}{|c|}{ East $^{1}$} \\
\hline & \multicolumn{2}{|c|}{ Men } & \multicolumn{2}{|c|}{ Women } & \multicolumn{2}{|c|}{ Men } & \multicolumn{2}{|c|}{ Women } \\
\hline & Part. & $\begin{array}{l}\text { Non- } \\
\text { Part. }\end{array}$ & Part. & $\begin{array}{l}\text { Non- } \\
\text { Part. }\end{array}$ & Part. & $\begin{array}{l}\text { Non- } \\
\text { Part. }\end{array}$ & Part. & $\begin{array}{l}\text { Non- } \\
\text { Part. }\end{array}$ \\
\hline & \multicolumn{8}{|c|}{ Means } \\
\hline Programme duration & 278.04 & & 304.88 & & 318.78 & & 333.27 & \\
\hline \multicolumn{9}{|l|}{ Socio-Demographic Variables } \\
\hline Age & 37.21 & 43.22 & 37.82 & 43.33 & 44.51 & 41.73 & 43.86 & 44.01 \\
\hline Married & 0.35 & 0.52 & 0.40 & 0.63 & 0.54 & 0.48 & 0.68 & 0.64 \\
\hline Number of children & 0.43 & 0.41 & 0.58 & 0.58 & 0.40 & 0.36 & 0.79 & 0.67 \\
\hline Duration last employment & 19.31 & 72.08 & 25.00 & 64.12 & 24.12 & 55.51 & 31.10 & 63.44 \\
\hline Number of placement propositions & 7.70 & 3.60 & 6.87 & 2.99 & 6.06 & 3.01 & 5.42 & 2.77 \\
\hline Last contact to job center & 2.48 & 2.54 & 2.53 & 2.40 & 2.54 & 2.79 & 2.59 & 2.78 \\
\hline Rehabilitation attendant & 0.05 & 0.06 & 0.04 & 0.03 & 0.07 & 0.07 & 0.03 & 0.05 \\
\hline \multirow[t]{2}{*}{ Placement restrictions } & 0.17 & 0.22 & 0.14 & 0.18 & 0.13 & 0.16 & 0.07 & 0.12 \\
\hline & \multicolumn{8}{|c|}{ Frequencies in \% } \\
\hline \multicolumn{9}{|l|}{ Health restrictions } \\
\hline No health restrictions & 74.30 & 68.23 & 78.23 & 73.29 & 76.57 & 74.99 & 85.08 & 79.55 \\
\hline Acc. DoR ${ }^{1}, 80 \%$ and over & 2.29 & 1.26 & 2.85 & 0.79 & 0.55 & 0.47 & 0.44 & 0.28 \\
\hline Acc. DoR, $50 \%$ to under $80 \%$ & 6.17 & 5.87 & 5.04 & 3.93 & 3.49 & 2.44 & 1.95 & 1.63 \\
\hline Acc. DoR, $30 \%$ to under $50 \%$ & 0.47 & 0.37 & 0.76 & 0.26 & 1.27 & 0.65 & 0.70 & 0.45 \\
\hline Acc. DoR, $30 \%$ to under $50 \%$, no equalis. ${ }^{2}$ & 2.76 & 4.74 & 1.71 & 3.52 & 1.47 & 1.74 & 0.71 & 1.16 \\
\hline Other health restrictions & 14.02 & 19.54 & 11.41 & 18.20 & 16.66 & 19.71 & 11.12 & 16.94 \\
\hline \multicolumn{9}{|l|}{ Qualification Variables } \\
\hline \multicolumn{9}{|l|}{ Professional training } \\
\hline Without compl. prof. training, no $\mathrm{CSE}^{3}$ & 26.03 & 15.48 & 7.98 & 10.64 & 8.72 & 6.01 & 3.54 & 4.91 \\
\hline Without compl. prof. training, with CSE & 36.59 & 33.64 & 37.26 & 39.30 & 19.90 & 17.09 & 18.73 & 20.94 \\
\hline Industrial training & 29.35 & 44.25 & 32.79 & 41.62 & 60.23 & 68.57 & 62.74 & 66.03 \\
\hline Full-time vocational school & 0.75 & 1.05 & 2.57 & 2.22 & 0.65 & 0.56 & 1.99 & 1.14 \\
\hline Technical school & 2.06 & 2.22 & 5.51 & 2.82 & 5.51 & 3.63 & 9.22 & 4.86 \\
\hline Polytechnic & 1.82 & 1.25 & 5.42 & 0.97 & 1.20 & 1.09 & 1.05 & 0.49 \\
\hline College, university & 3.41 & 2.12 & 8.46 & 2.44 & 3.80 & 3.05 & 2.74 & 1.63 \\
\hline \multicolumn{9}{|l|}{ Occupational group } \\
\hline Plant cultivation, breeding, fishery & 8.69 & 3.72 & 2.00 & 1.75 & 6.77 & 5.35 & 7.27 & 5.18 \\
\hline Mining, mineral extraction & 0.23 & 0.62 & 0.00 & 0.02 & 0.14 & 0.27 & 0.00 & 0.05 \\
\hline Manufacturing & 52.10 & 47.71 & 14.64 & 23.53 & 52.43 & 52.82 & 18.67 & 19.73 \\
\hline Technical professions & 2.85 & 5.34 & 1.90 & 2.08 & 6.91 & 5.97 & 5.20 & 3.18 \\
\hline Service professions & 33.64 & 40.71 & 79.56 & 71.16 & 32.97 & 32.67 & 68.60 & 70.34 \\
\hline Other professions & 2.48 & 0.12 & 1.90 & 0.06 & 0.79 & 0.04 & 0.26 & 0.02 \\
\hline \multicolumn{9}{|l|}{ Professional rank } \\
\hline Unskilled Worker & 31.96 & 24.25 & 13.78 & 17.05 & 30.47 & 21.51 & 24.97 & 20.55 \\
\hline Skilled Worker & 7.10 & 15.29 & 3.71 & 5.71 & 20.01 & 29.40 & 14.18 & 15.96 \\
\hline White-collar worker, simple occupations & 5.05 & 7.24 & 18.54 & 18.45 & 4.92 & 4.20 & 10.55 & 9.13 \\
\hline White-collar worker, advanced occupations & 3.69 & 4.71 & 9.41 & 4.35 & 1.68 & 2.01 & 1.83 & 1.85 \\
\hline Other & 52.20 & 48.52 & 54.56 & 54.45 & 42.92 & 42.87 & 48.48 & 52.50 \\
\hline Qualification (with work experience) & 87.24 & 92.56 & 84.89 & 92.56 & 89.98 & 89.16 & 90.11 & 89.62 \\
\hline Career Variables & & & & & & & & \\
\hline Duration of unemployment & & & & & & & & \\
\hline$<13$ & 26.07 & 27.66 & 22.53 & 22.09 & 19.77 & 33.96 & 11.42 & 16.27 \\
\hline $13-52$ & 34.77 & 31.54 & 38.31 & 35.75 & 42.68 & 35.29 & 39.13 & 34.84 \\
\hline$>52$ & 39.16 & 40.79 & 39.16 & 42.16 & 37.55 & 30.75 & 49.45 & 48.89 \\
\hline Programme before unemployment & & & & & & & & \\
\hline No further education or programme & 71.45 & 89.95 & 66.83 & 91.14 & 52.84 & 82.92 & 42.72 & 72.15 \\
\hline Further education compl., cont. education & 9.77 & 6.97 & 12.36 & 7.38 & 14.16 & 8.74 & 23.54 & 16.65 \\
\hline Further education compl., voc. adjustment & 1.07 & 0.48 & 0.57 & 0.25 & 5.57 & 2.90 & 4.77 & 3.07 \\
\hline Job-preparative measure & 0.05 & 0.05 & 0.57 & 0.04 & 0.21 & 0.14 & 0.08 & 0.12 \\
\hline Job creation scheme & 16.92 & 1.56 & 18.54 & 0.79 & 26.44 & 4.56 & 28.58 & 7.62 \\
\hline Rehabilitation measure & 0.75 & 0.98 & 1.14 & 0.41 & 0.79 & 0.74 & 0.32 & 0.39 \\
\hline
\end{tabular}

\footnotetext{
${ }^{1} \mathrm{DoR}=$ degree of restriction

${ }^{2}$ People with accepted degree of restriction, but no equalisation to other persons with the same DoR.

${ }^{3} \mathrm{CSE}=$ Certificate for secondary education
} 


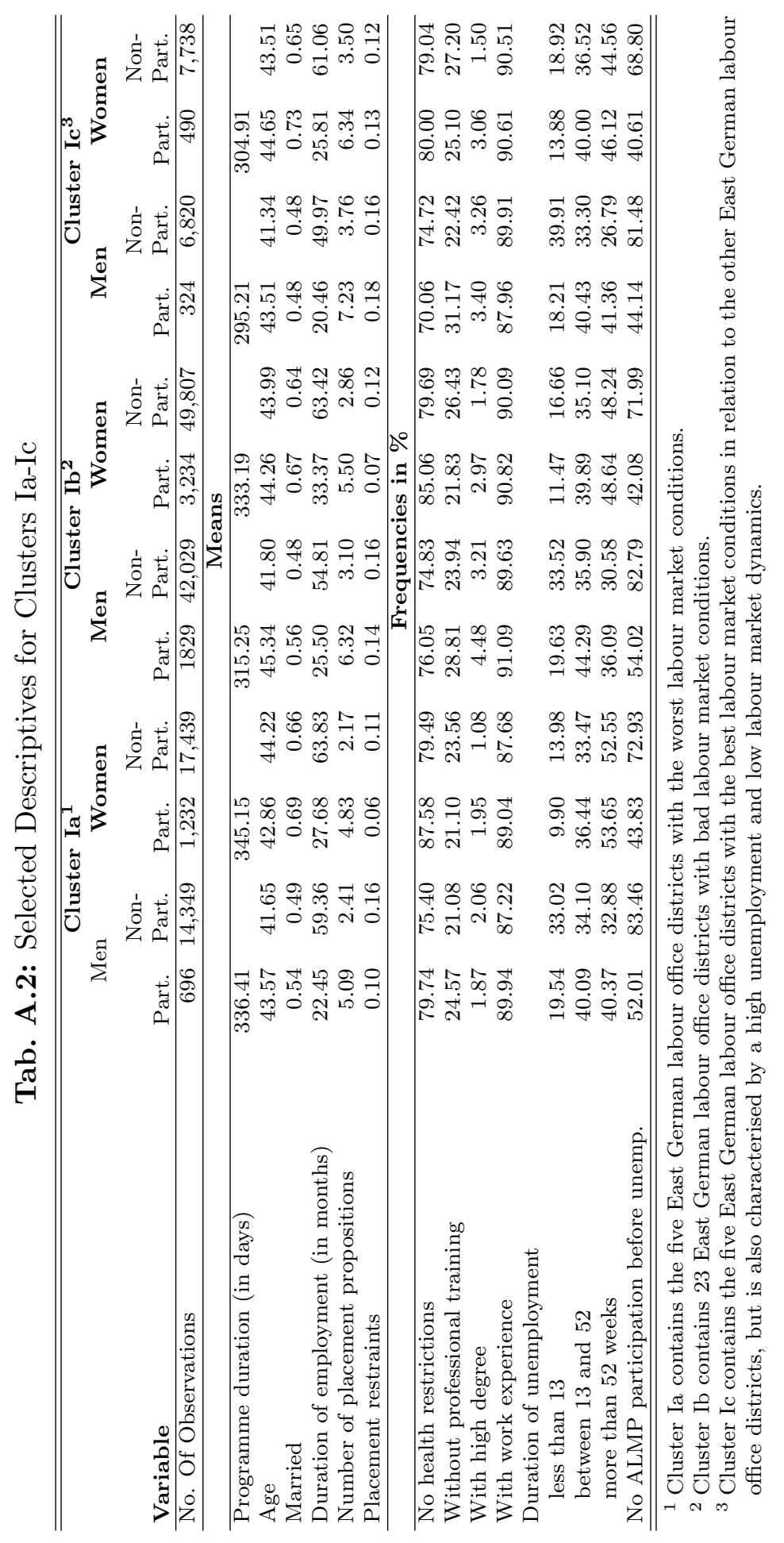




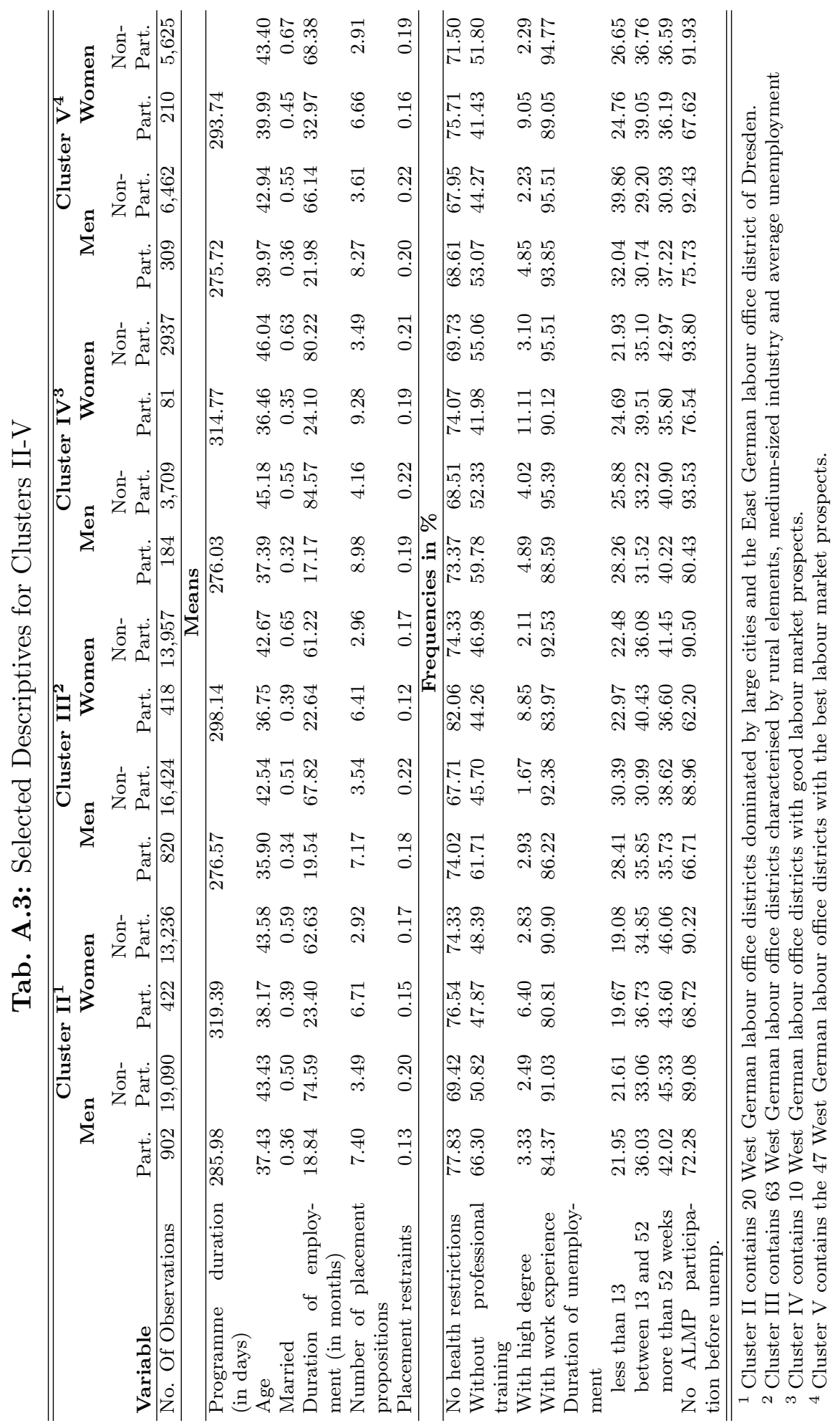


Tab. A.4: Estimation Results of the Logit-Models for the Propensity Score

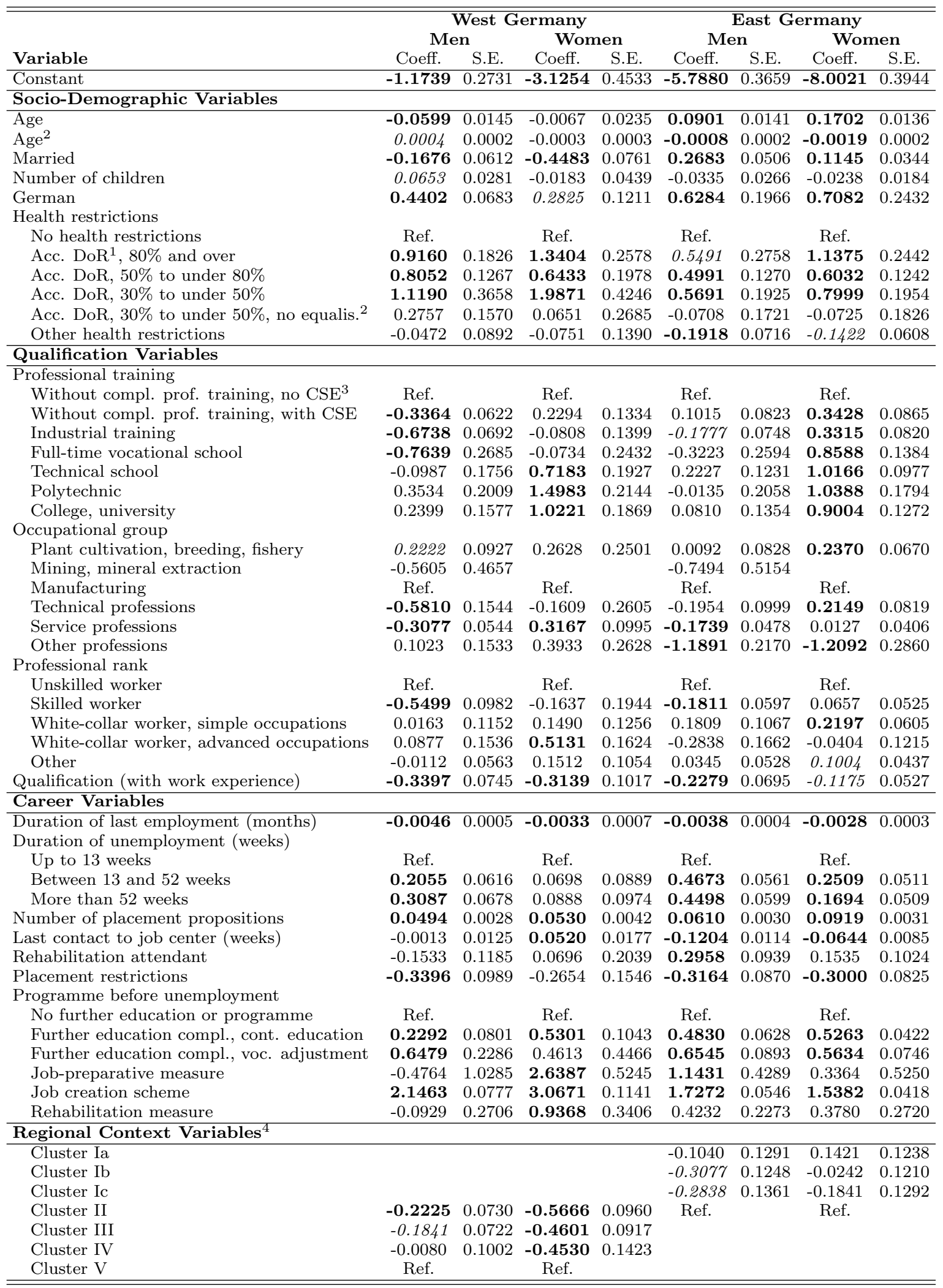

Bold letters indicate significance at the $1 \%$ level. Italic letters refer to the $5 \%$ level.

${ }^{1}$ DoR $=$ degree of restriction.

2 People with accepted degree of restriction, but no equalisation to other persons with the same DoR.

$3 \mathrm{CSE}=$ Certificate for secondary education

${ }^{4}$ Cluster according to the classification as described in table B.1. 
Tab. A.5: Standardised Bias Main Groups - Before and After Matching

\begin{tabular}{|c|c|c|c|c|c|c|c|c|}
\hline & \multicolumn{4}{|c|}{ West Germany } & \multicolumn{4}{|c|}{ East Germany } \\
\hline & \multicolumn{2}{|c|}{ Men } & \multicolumn{2}{|c|}{ Women } & \multicolumn{2}{|c|}{ Men } & \multicolumn{2}{|c|}{ Women } \\
\hline & Before & After & Before & After & Before & After & Before & After \\
\hline \multicolumn{9}{|l|}{ Socio-Demographic Variables } \\
\hline Age & 48.64 & 4.22 & 47.62 & 5.64 & 22.84 & 1.09 & 1.37 & 2.49 \\
\hline Married & 34.17 & 6.28 & 48.47 & 8.16 & 11.29 & 0.89 & 6.98 & 0.47 \\
\hline Number of children & 2.25 & 1.11 & 0.75 & 0.58 & 5.32 & 1.32 & 12.20 & 1.26 \\
\hline German & 8.19 & 1.30 & 13.97 & 3.27 & 6.98 & 1.84 & 6.29 & 0.69 \\
\hline \multicolumn{9}{|l|}{ Health restrictions } \\
\hline No health restrictions & 13.44 & 5.27 & 11.55 & 5.31 & 3.69 & 0.81 & 14.55 & 3.24 \\
\hline Acc. DoR, $180 \%$ and over & 7.83 & 0.33 & 15.47 & 1.96 & 1.14 & 0.90 & 2.70 & 0.89 \\
\hline Acc. DoR, $50 \%$ to under $80 \%$ & 1.25 & 1.82 & 5.34 & 2.59 & 6.16 & 0.19 & 2.35 & 1.27 \\
\hline Acc. DoR, $30 \%$ to under $50 \%$ & 1.59 & 3.97 & 6.97 & 4.10 & 6.32 & 0.90 & 3.29 & 1.81 \\
\hline Acc. DoR, $30 \%$ to under $50 \%$, no equalis. ${ }^{2}$ & 10.46 & 3.62 & 11.36 & 4.99 & 2.14 & 1.16 & 4.59 & 0.98 \\
\hline Other health restrictions & 14.80 & 2.89 & 19.22 & 1.26 & 7.92 & 0.73 & 16.81 & 4.76 \\
\hline \multicolumn{9}{|l|}{ Qualification Variables } \\
\hline \multicolumn{9}{|l|}{ Professional training } \\
\hline Without compl. prof. training, no $\mathrm{CSE}^{3}$ & 26.22 & 4.05 & 9.12 & 2.59 & 10.39 & 1.79 & 6.82 & 1.65 \\
\hline Without compl. prof. training, with CSE & 6.19 & 1.57 & 4.18 & 5.01 & 7.25 & 0.77 & 5.55 & 3.22 \\
\hline Industrial training & 31.27 & 0.52 & 18.34 & 4.99 & 17.50 & 0.70 & 6.87 & 1.64 \\
\hline Full-time vocational school & 3.20 & 1.13 & 2.26 & 2.45 & 1.15 & 3.79 & 6.81 & 0.84 \\
\hline Technical school & 1.10 & 2.77 & 13.50 & 0.00 & 9.02 & 1.19 & 17.06 & 2.10 \\
\hline Polytechnic & 4.68 & 1.09 & 25.51 & 2.48 & 1.01 & 0.96 & 6.48 & 1.52 \\
\hline College, university & 7.86 & 1.06 & 26.76 & 2.88 & 4.11 & 2.02 & 7.60 & 0.84 \\
\hline \multicolumn{9}{|l|}{ Occupational group } \\
\hline Plant cultivation, breeding, fishery & 20.69 & 1.52 & 1.79 & 0.00 & 5.98 & 0.00 & 8.63 & 1.32 \\
\hline Mining, mineral extraction & 5.95 & 2.17 & 0.00 & & 3.04 & 3.51 & 0.00 & \\
\hline Manufacturing & 8.80 & 0.09 & 22.79 & 5.31 & 0.78 & 0.07 & 2.72 & 0.66 \\
\hline Technical professions & 12.59 & 0.00 & 1.27 & 4.83 & 3.80 & 1.73 & 10.10 & 0.09 \\
\hline Service professions & 14.66 & 1.30 & 19.54 & 5.92 & 0.63 & 0.87 & 3.86 & 0.00 \\
\hline Other professions & 3.97 & 1.48 & 3.52 & 0.75 & 15.85 & 0.38 & 13.43 & 1.79 \\
\hline \multicolumn{9}{|l|}{ Professional rank } \\
\hline Unskilled worker & 17.22 & 2.52 & 9.01 & 2.04 & 20.54 & 1.92 & 10.55 & 1.14 \\
\hline Skilled worker & 26.18 & 6.56 & 9.45 & 3.09 & 21.91 & 6.40 & 4.98 & 3.54 \\
\hline White-collar worker, simple occupations & 9.13 & 1.06 & 0.20 & 4.66 & 3.46 & 0.80 & 4.75 & 3.04 \\
\hline White-collar worker, advanced occupations & 5.06 & 3.14 & 20.09 & 4.58 & 2.52 & 1.65 & 0.21 & 1.21 \\
\hline Other & 7.36 & 1.51 & 0.22 & 3.89 & 0.10 & 4.00 & 8.05 & 3.58 \\
\hline Qualification (with work experience) & 17.71 & 0.70 & 24.41 & 3.89 & 2.68 & 1.69 & 1.65 & 0.13 \\
\hline \multicolumn{9}{|l|}{ Career Variables } \\
\hline Duration of last employment (months) & 57.08 & 6.26 & 51.99 & 9.34 & 36.23 & 0.77 & 37.47 & 1.44 \\
\hline Duration of unemployment (weeks) & & & & & & & & \\
\hline Up to 13 weeks & 3.58 & 2.92 & 1.07 & 1.45 & 32.44 & 8.44 & 14.09 & 1.45 \\
\hline Between 13 and 52 weeks & 6.85 & 3.83 & 5.31 & 2.93 & 15.20 & 2.42 & 8.89 & 0.08 \\
\hline More than 52 weeks & 3.34 & 1.16 & 6.12 & 4.21 & 14.38 & 4.22 & 1.13 & 0.84 \\
\hline Number of placement propositions & 59.16 & 4.74 & 60.13 & 0.50 & 57.97 & 1.79 & 64.89 & 0.04 \\
\hline Last contact to job center (weeks) & 2.55 & 0.38 & 6.04 & 2.77 & 12.16 & 1.35 & 9.21 & 0.19 \\
\hline Rehabilitation attendant & 4.65 & 0.43 & 5.74 & 2.17 & 0.11 & 0.78 & 7.83 & 2.49 \\
\hline Placement restrictions & 12.85 & 4.28 & 9.46 & 6.48 & 7.56 & 1.49 & 15.11 & 2.32 \\
\hline Programme before unemployment & & & & & & & & \\
\hline No further education or programme & 48.23 & 2.85 & 62.49 & 2.96 & 68.03 & 0.62 & 62.35 & 0.48 \\
\hline Further education compl., cont. education & 10.11 & 5.34 & 16.75 & 2.45 & 17.08 & 4.98 & 17.26 & 4.67 \\
\hline Further education compl., voc. adjustment & 6.73 & 3.36 & 5.04 & 1.36 & 13.31 & 3.74 & 8.75 & 0.56 \\
\hline Job-preparative measure & 0.15 & 0.00 & 9.67 & 2.42 & 1.52 & 0.73 & 1.37 & 0.00 \\
\hline Job creation scheme & 54.99 & 9.35 & 62.93 & 2.47 & 63.39 & 5.84 & 56.58 & 3.69 \\
\hline Rehabilitation measure & 2.55 & 0.00 & 8.39 & 1.78 & 0.56 & 1.49 & 1.27 & 0.00 \\
\hline Regional Context Variables $^{4}$ & & & & & & & & \\
\hline Cluster Ia & & & & & 3.94 & 0.48 & 3.98 & 2.39 \\
\hline Cluster Ib & & & & & 4.83 & 0.21 & 1.84 & 2.56 \\
\hline Cluster Ic & & & & & 1.78 & 0.76 & 1.29 & 1.20 \\
\hline Cluster II & 2.13 & 2.31 & 3.41 & 1.51 & 0.71 & 0.88 & 3.24 & 1.31 \\
\hline Cluster III & 2.21 & 0.78 & 2.11 & 0.21 & & & & \\
\hline Cluster IV & 0.67 & 2.06 & 3.23 & 0.39 & & & & \\
\hline Cluster V & 0.61 & 0.54 & 9.15 & 1.78 & & & & \\
\hline Mean (unweighted average) & 13.85 & 2.46 & 15.36 & 3.14 & 11.84 & 1.81 & 10.93 & 1.56 \\
\hline
\end{tabular}


Tab. A.6: Mean Standardised Bias in the Seven Clusters ${ }^{1}$

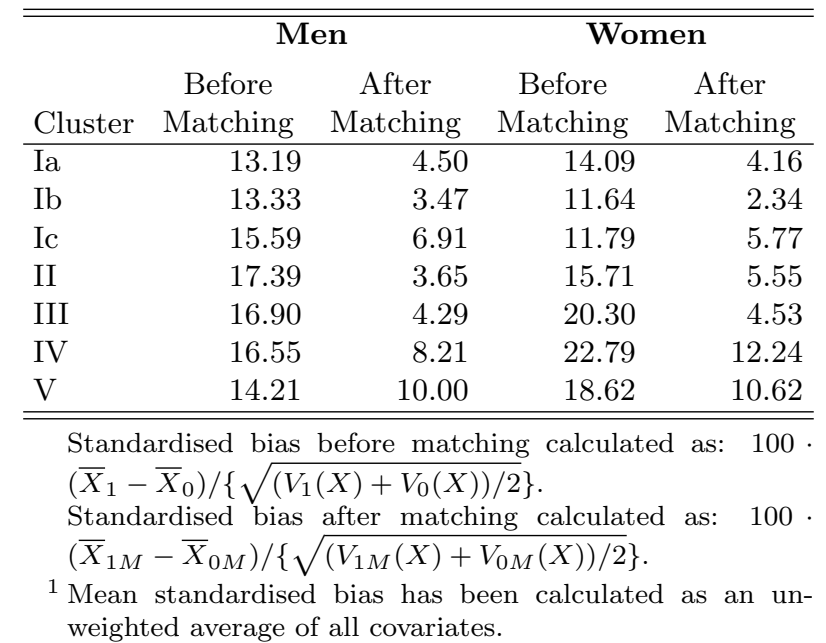




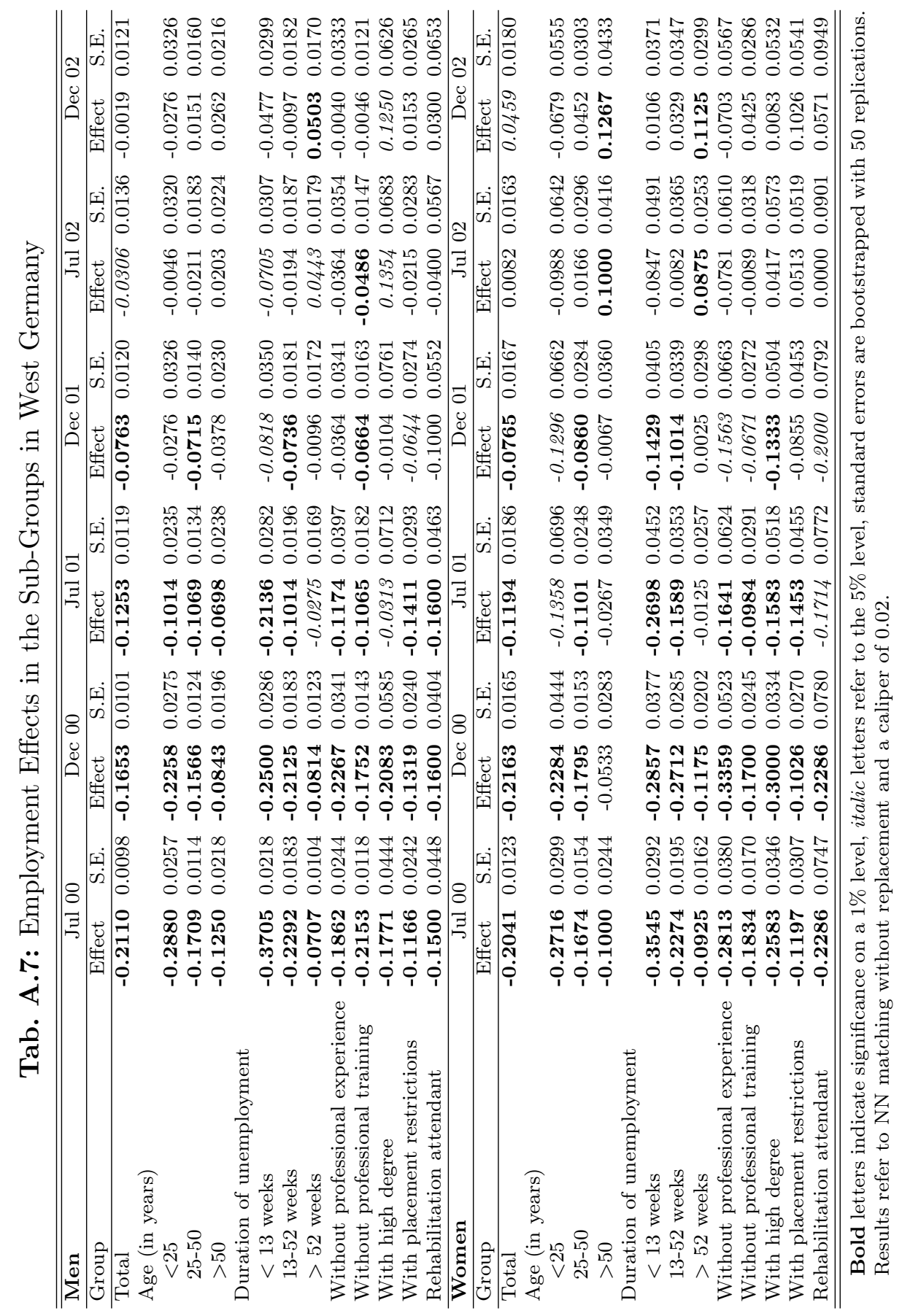




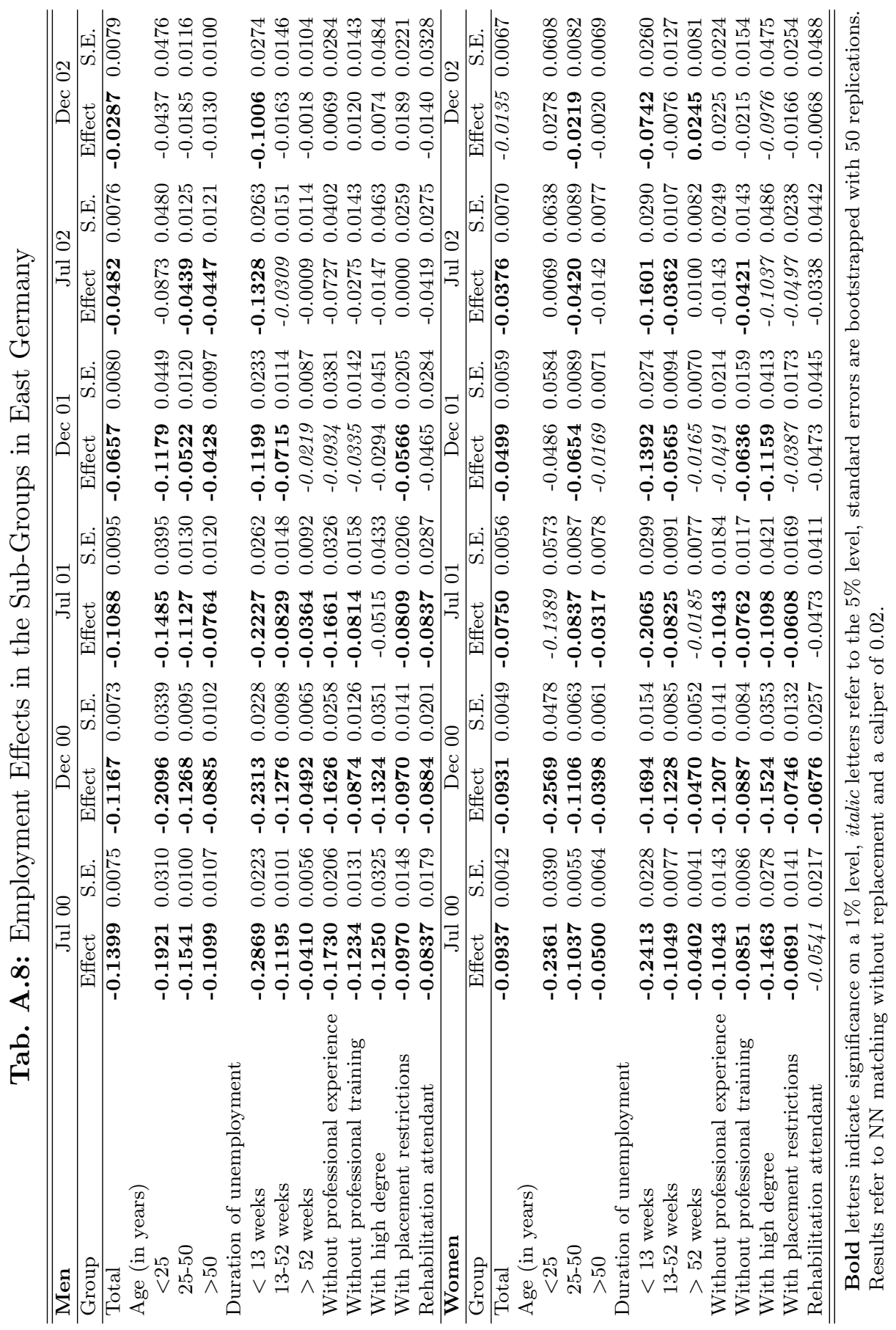




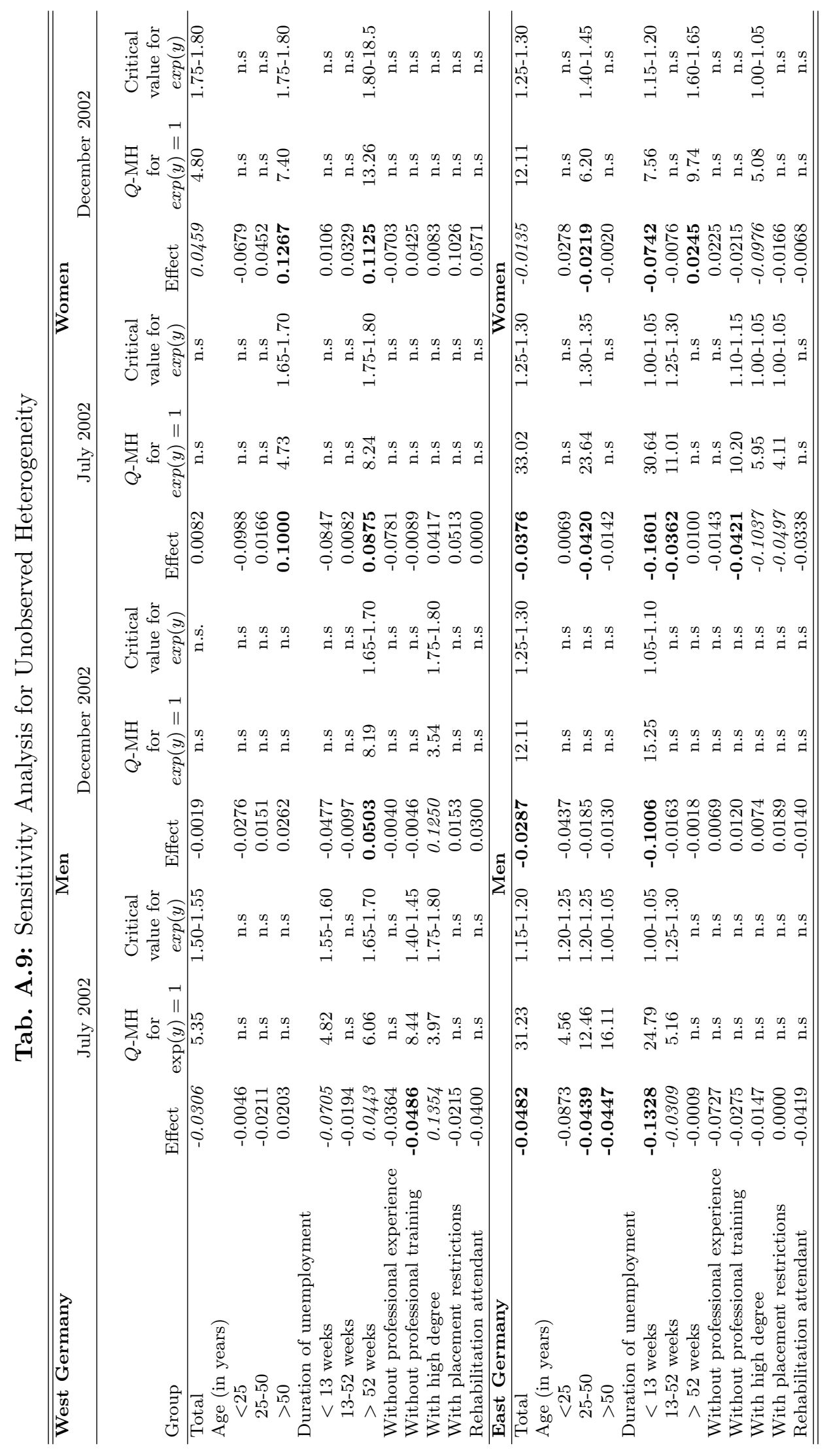



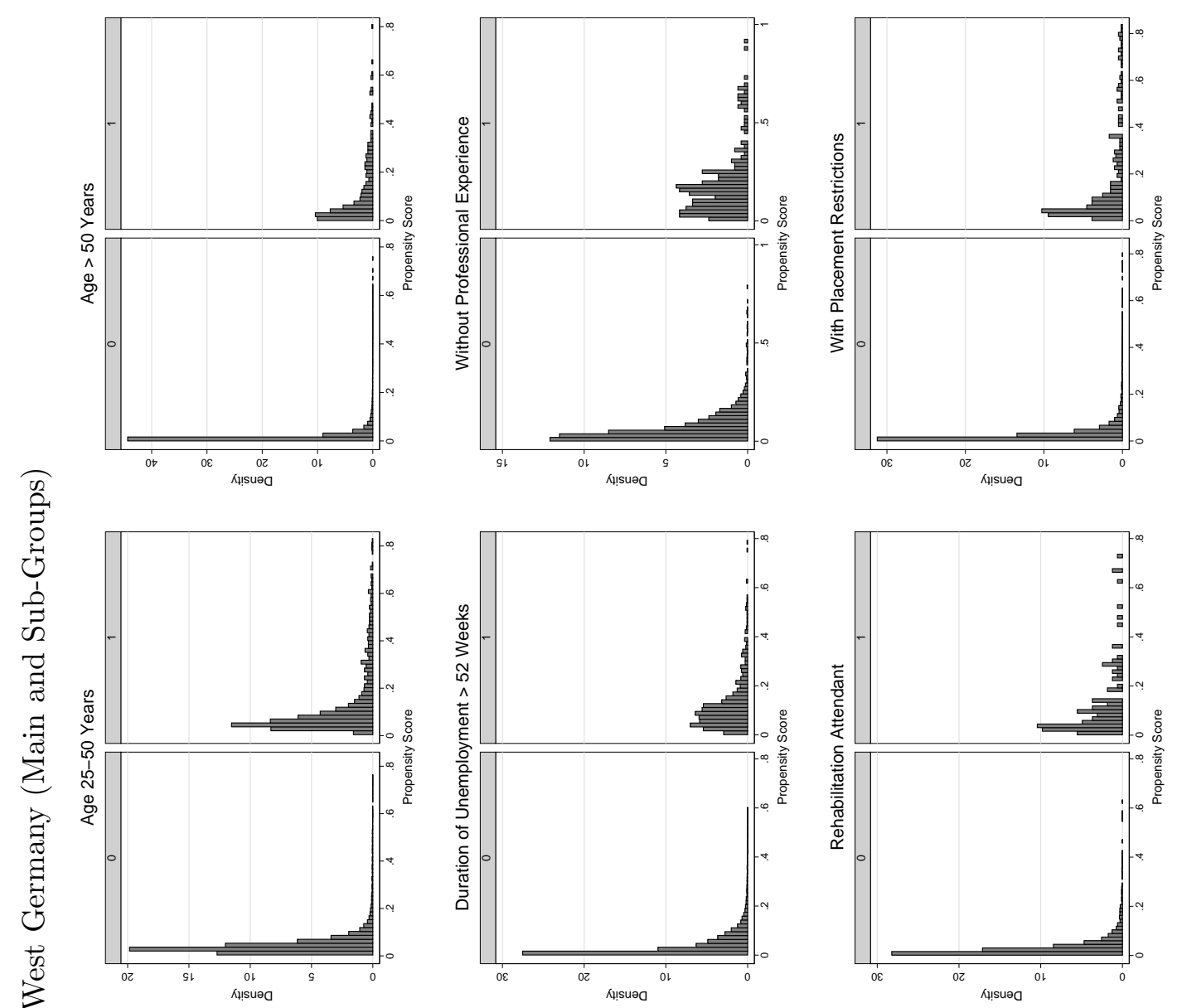

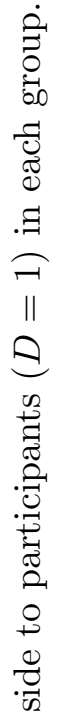
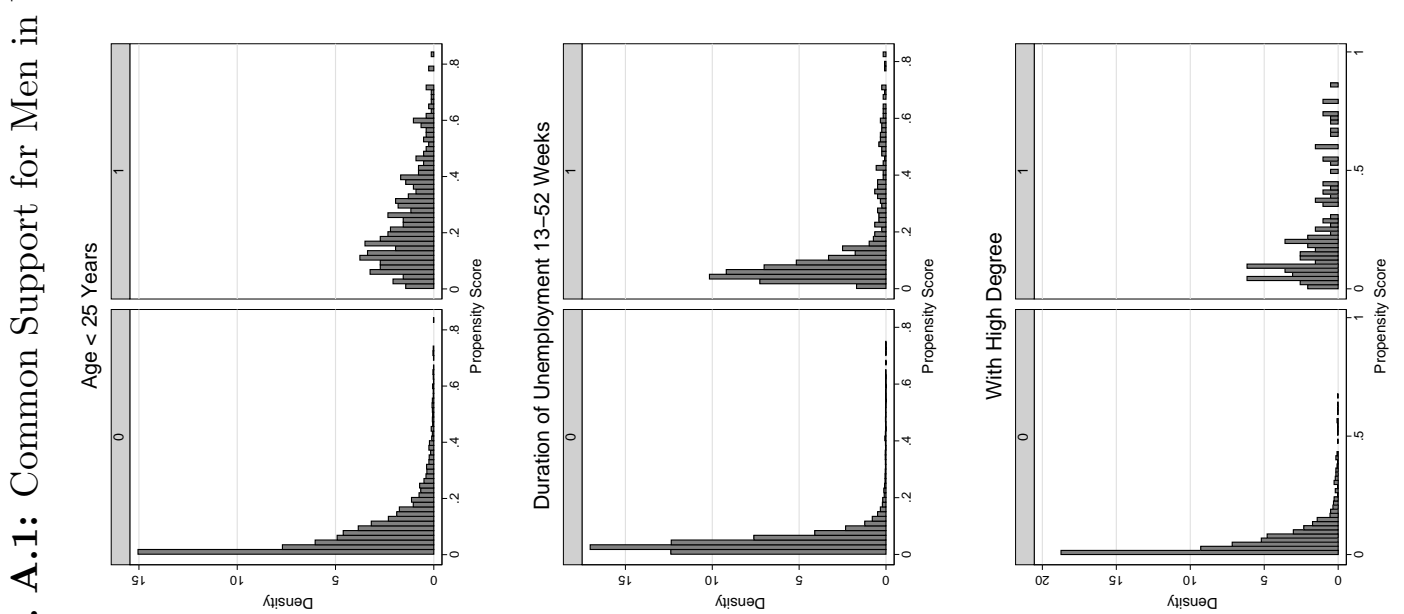

$\stackrel{\dot{0}}{\dot{1}}$
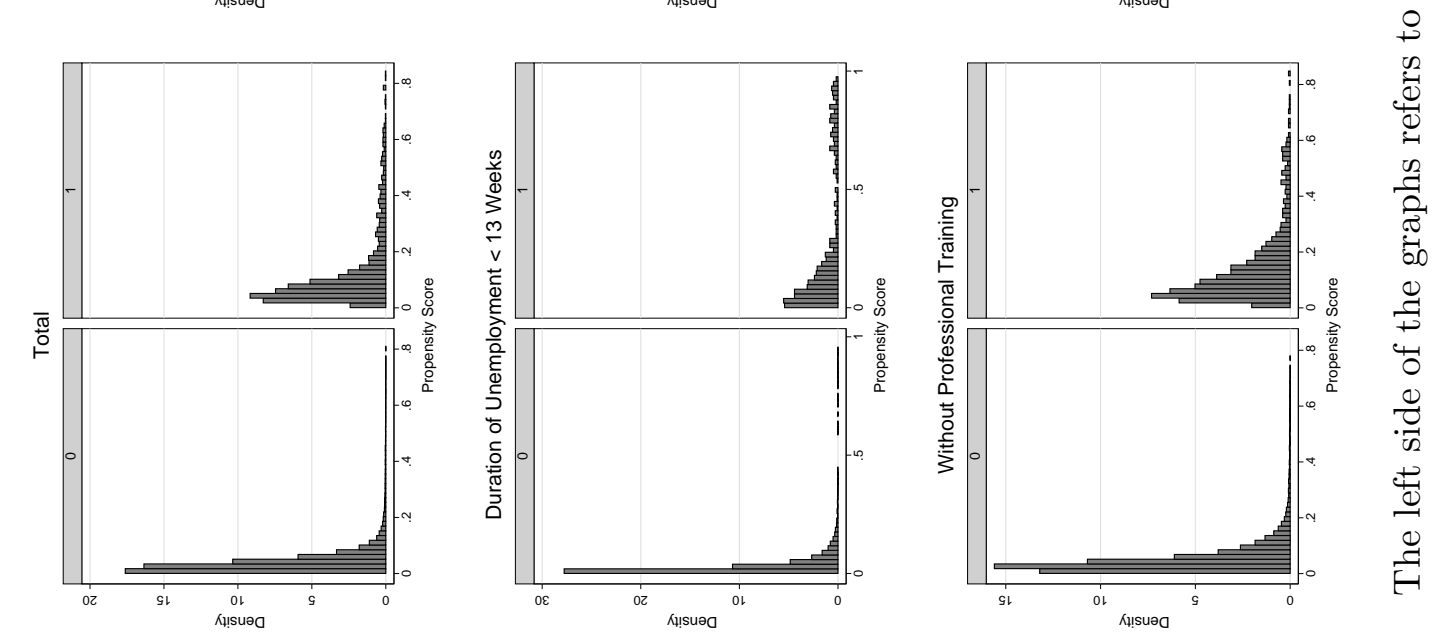

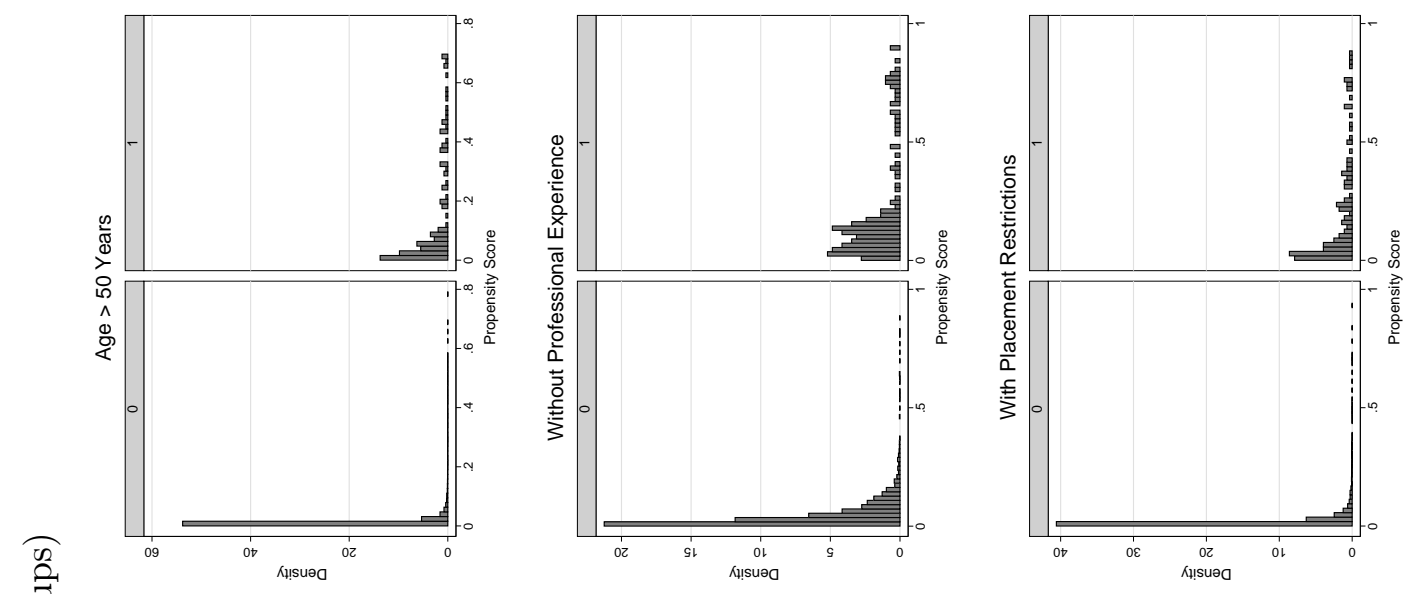

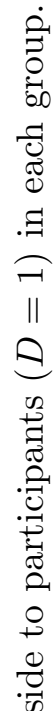
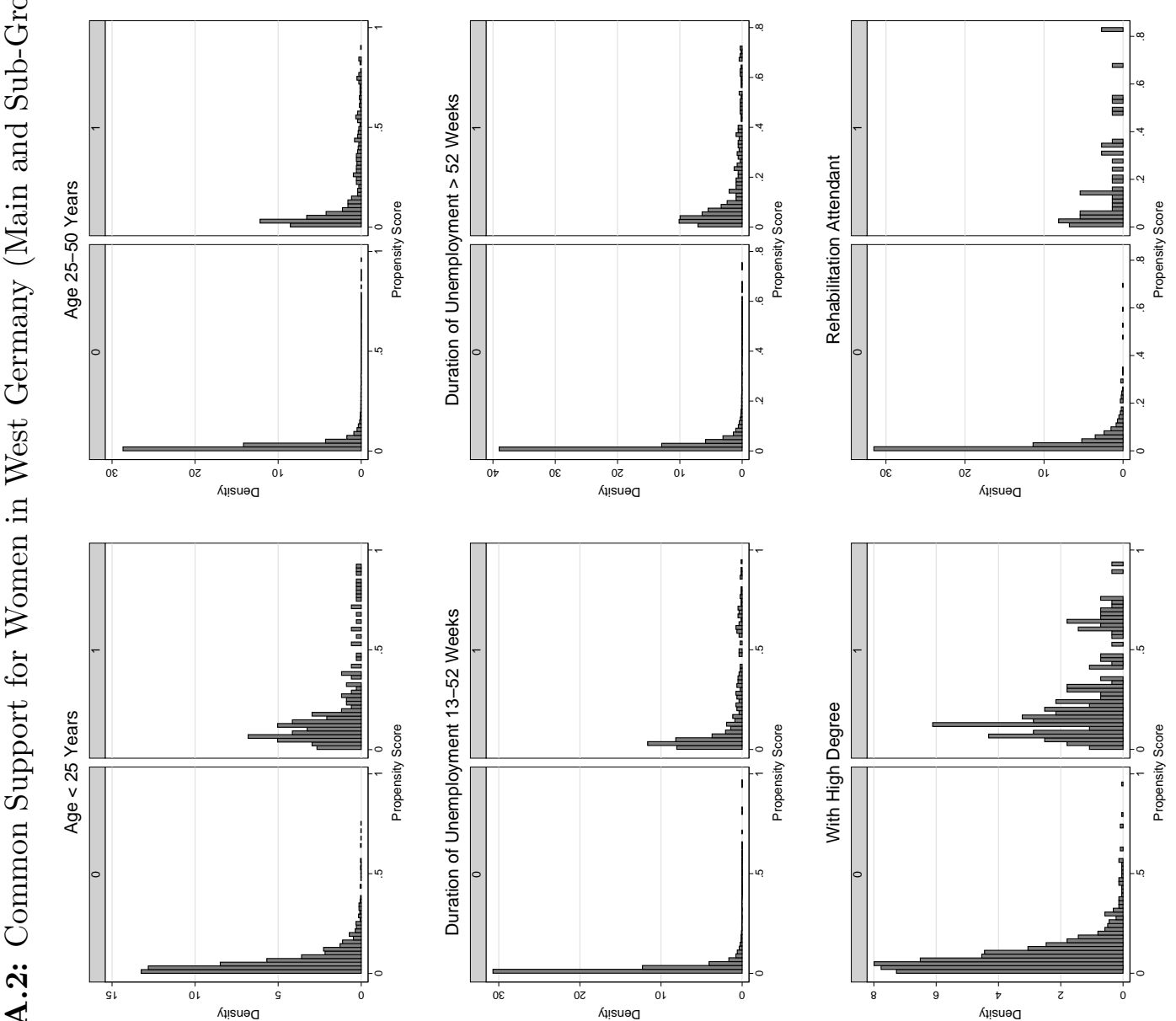

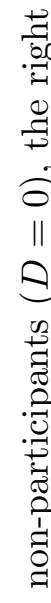

$\stackrel{\infty 00}{10}$
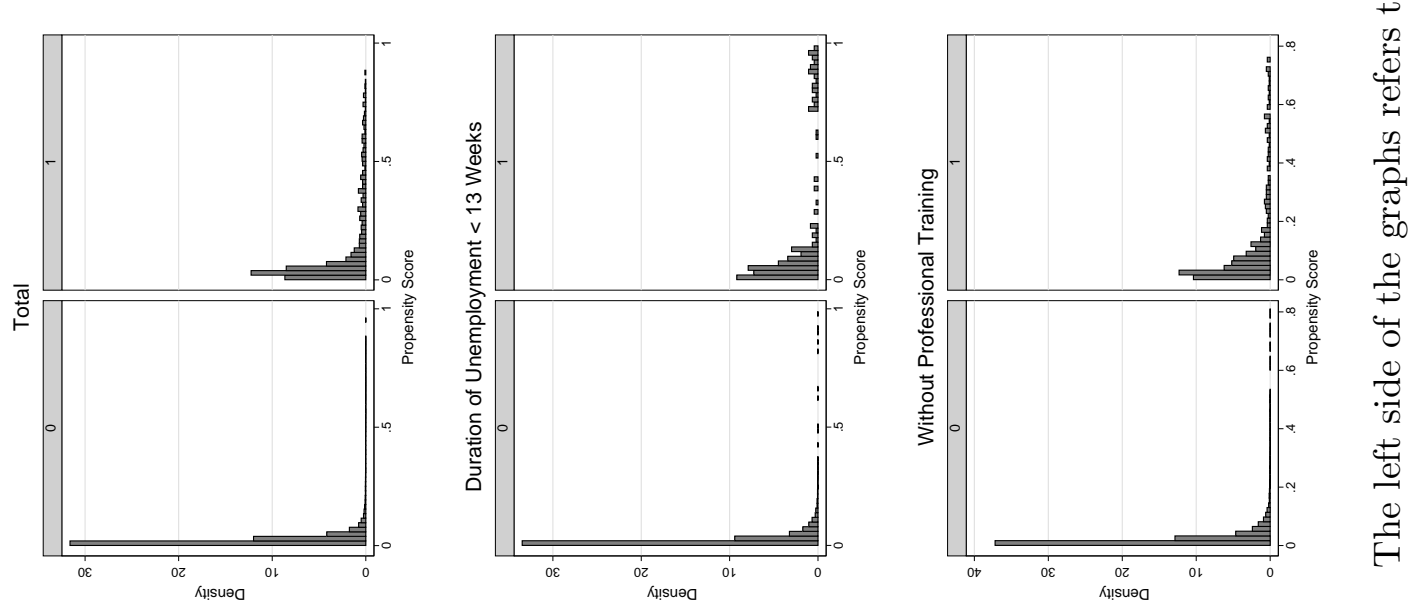

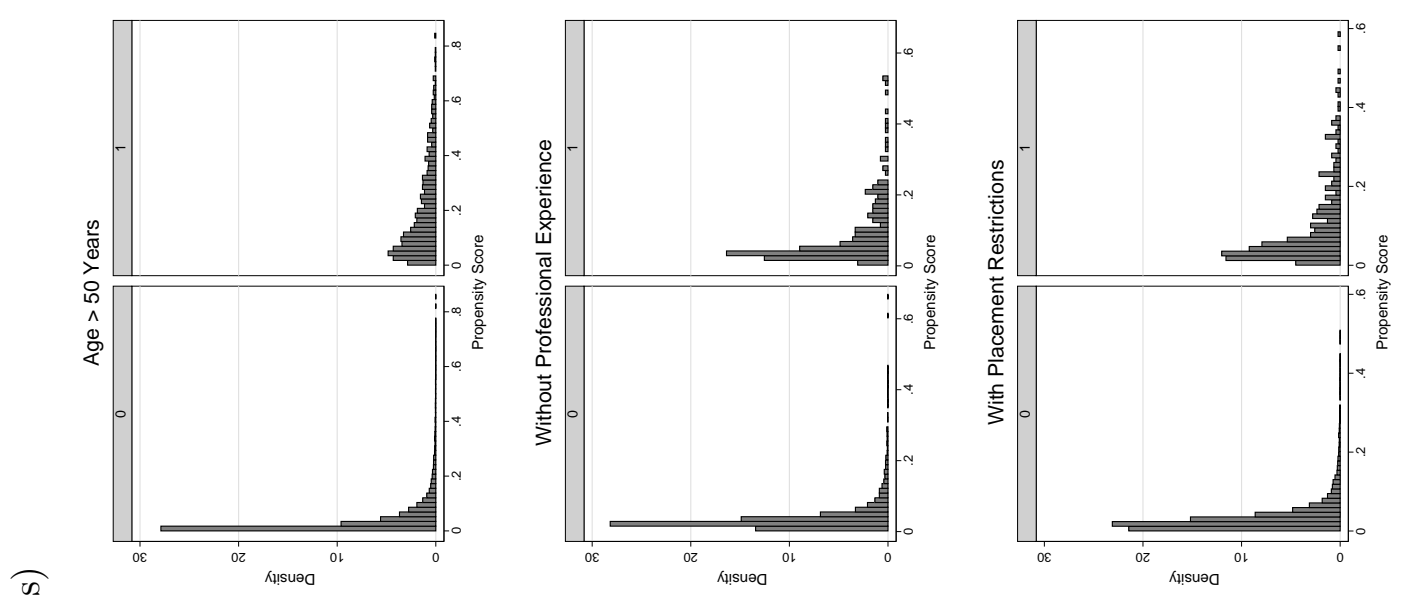

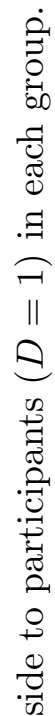
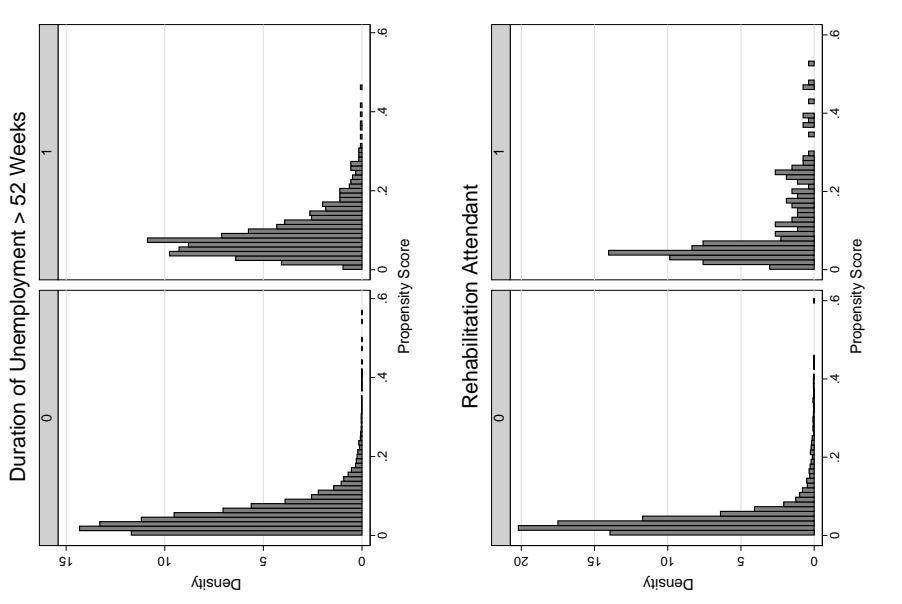

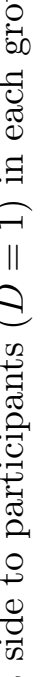

$\nexists$
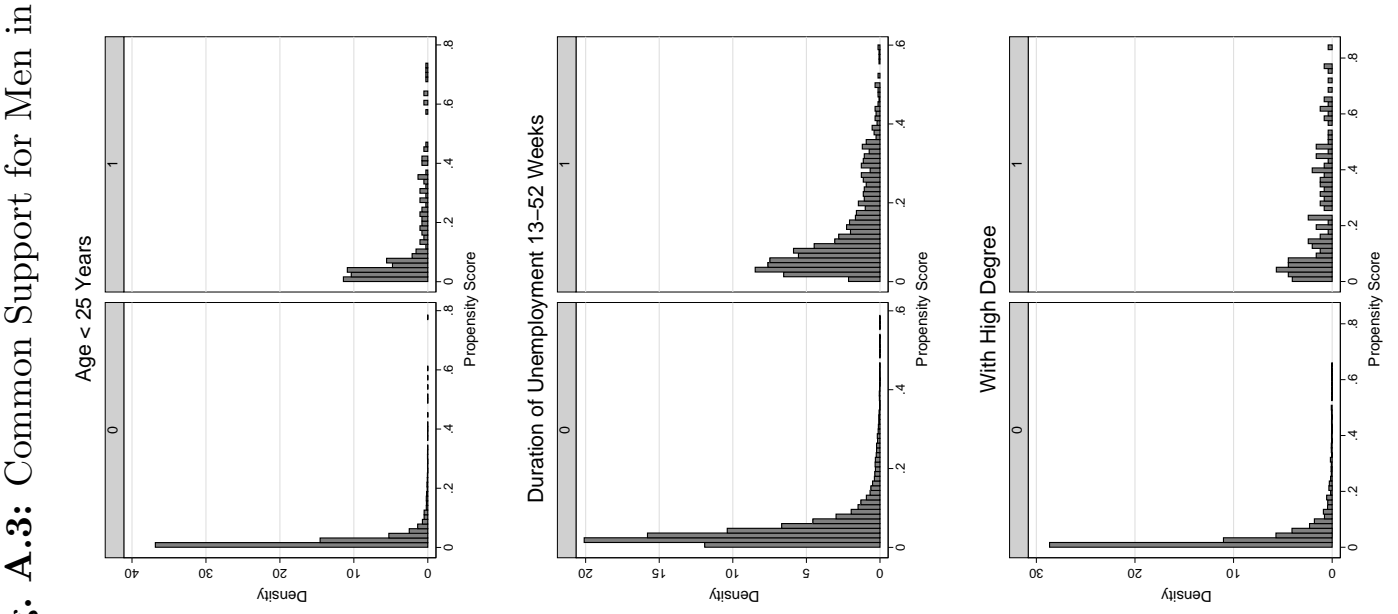

$\stackrel{\dot{0}}{\dot{1}}$
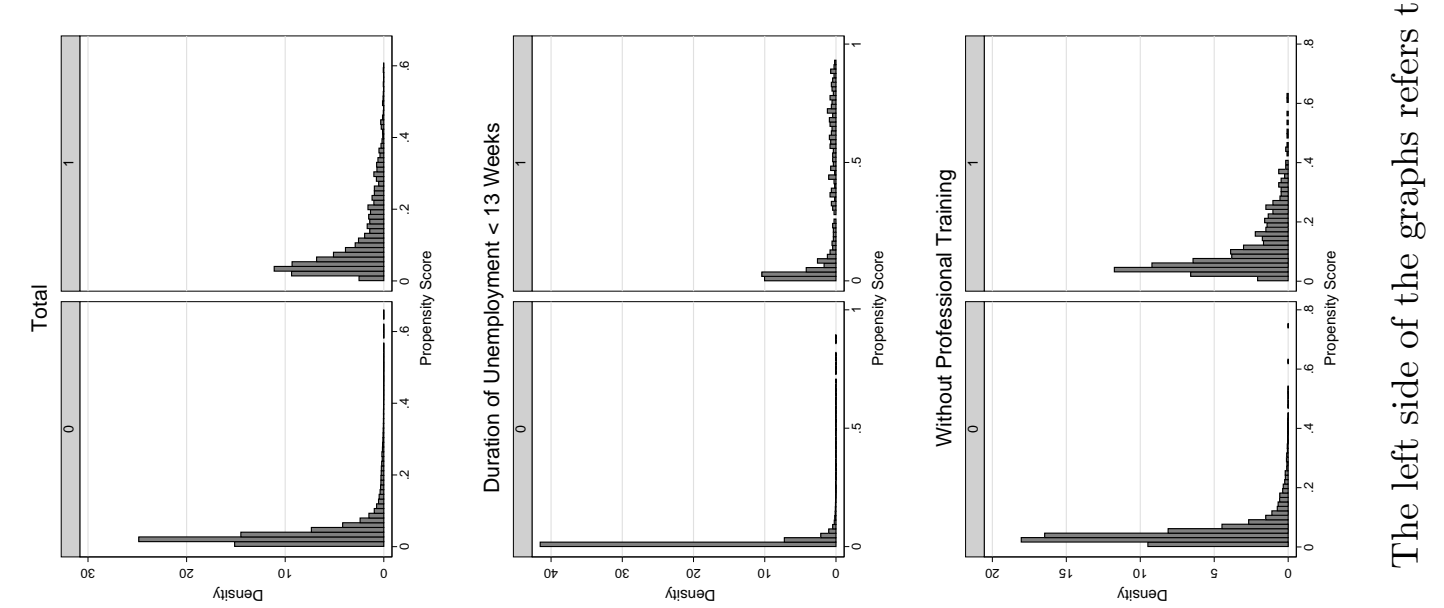

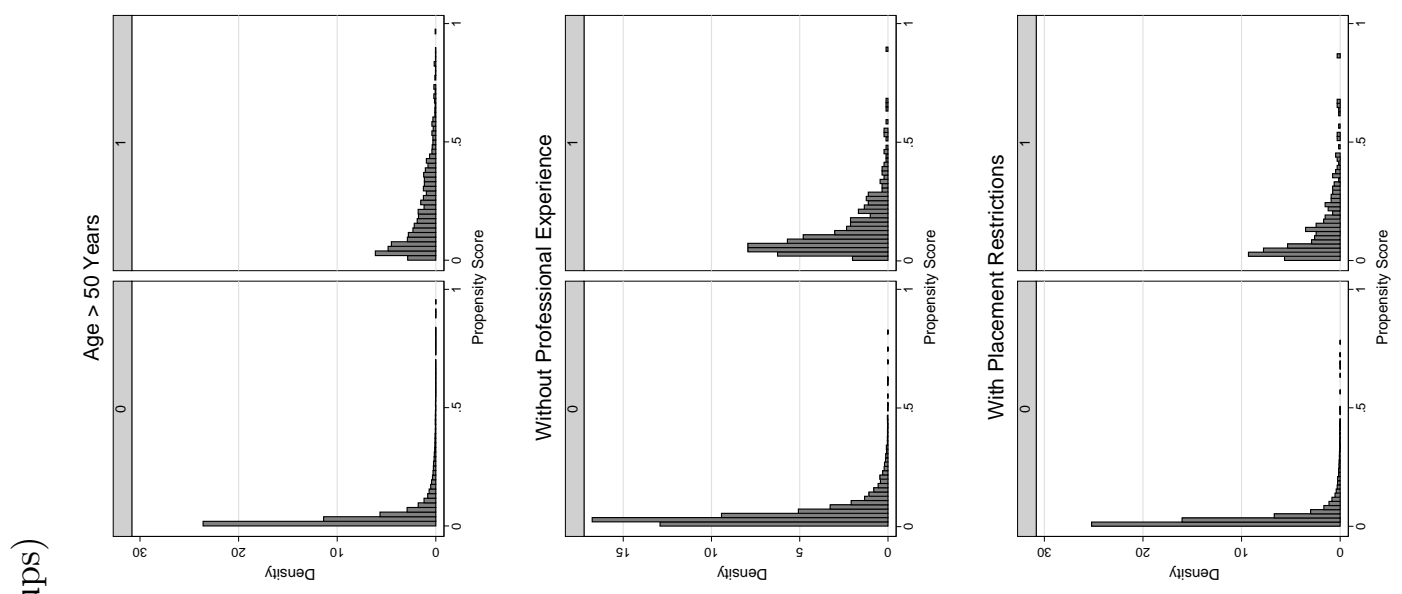

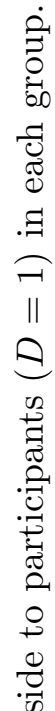
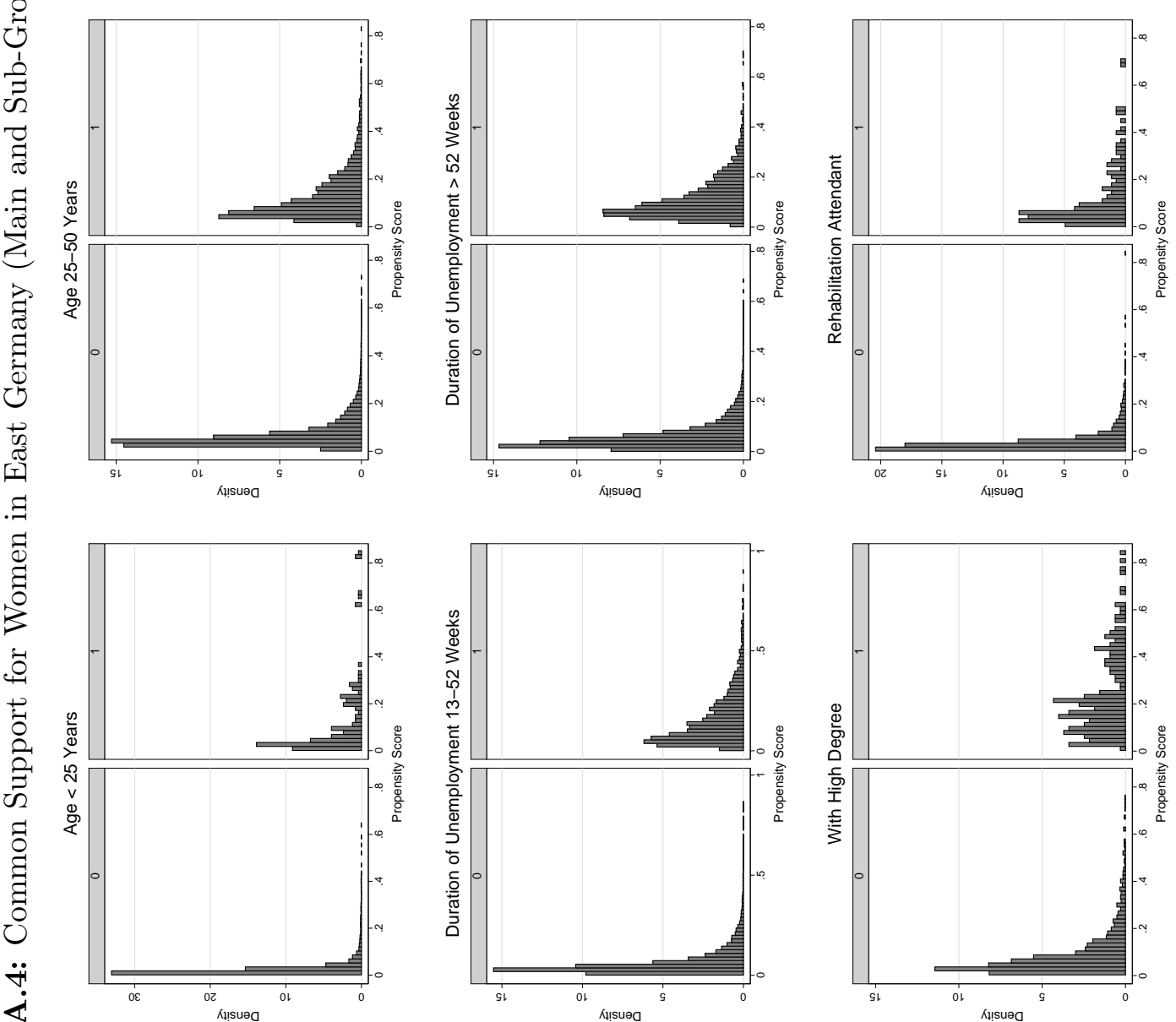

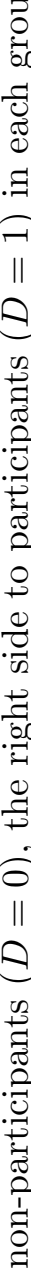

$\stackrel{\dot{0}}{\dot{0}}$
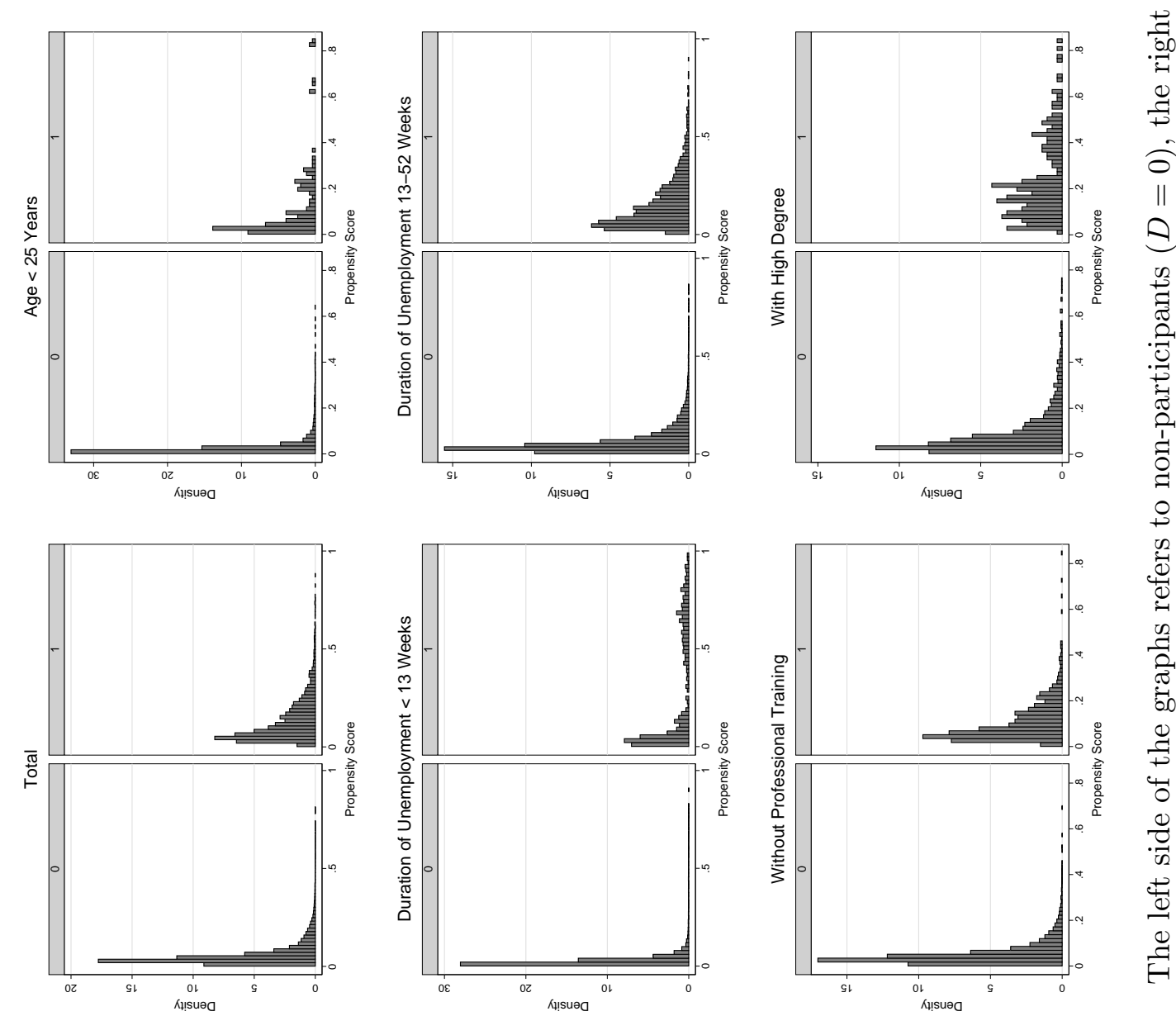


\section{B Regional Clusters}

To account for the situation on the regional labour market we use the classification of similar and comparable labour office districts of the FEA by Blien et al.(2004). The first group (Ia) contains the five East German districts with the worst labour market conditions, characterised by the highest underemployment, a population density below average and the slightest labour market dynamics. The 23 'typical' East German labour office districts are pooled in cluster Ib and have high underemployment and minor labour market dynamics. Although the underemployment is above average and the dynamics are only moderate in labour office districts of cluster Ic, the five districts have the most promising labour market situation of East Germany. Cluster II contains 21 labour office districts dominated by large cities with an above average to a high underemployment, a high population density, moderate labour market dynamics, a high number of welfare recipients and an above average tertiarisation of jobs. Except the labour office of Dresden, all districts are in West Germany. The majority of West German labour office districts (63) belong to cluster III. An average to an above average underemployment, little labour market dynamics and a low population density characterise these districts with rural elements and medium-sized industry. Cluster IV pools West German labour office districts with advantageous labour market prospects. These are ten big city districts with the highest labour market dynamics, an underemployment below average, a high tertiarisation of jobs, but also an above average number of welfare recipients. The last cluster (V) contains the 46 labour office districts with the best labour market situation. Underemployment and also the number of welfare recipients is the lowest in Germany.

Tab. B.1: Classification of labour office districts in Germany

\begin{tabular}{|c|c|c|c|c|c|c|}
\hline \multirow[b]{2}{*}{ Cluster } & \multirow[b]{2}{*}{ Description } & \multirow{2}{*}{$\begin{array}{l}\text { Number of } \\
\text { districts }\end{array}$} & \multicolumn{4}{|c|}{ Number of participants } \\
\hline & & & Men & in $\%$ & Women & in $\%$ \\
\hline Ia & $\begin{array}{l}\text { East German labour office districts with } \\
\text { worst labour market conditions }\end{array}$ & 5 & 696 & 13.7 & 1,232 & 20.2 \\
\hline $\mathrm{Ib}$ & $\begin{array}{l}\text { East German labour office districts with } \\
\text { bad labour market conditions }\end{array}$ & 23 & 1,829 & 36.1 & 3,234 & 53.1 \\
\hline Ic & $\begin{array}{l}\text { East German labour office districts with } \\
\text { high unemployment }\end{array}$ & 5 & 324 & 6.4 & 490 & 8.1 \\
\hline $\mathrm{II}^{1}$ & $\begin{array}{l}\text { Labour office districts dominated by large } \\
\text { cities }\end{array}$ & 21 & 902 & 17.8 & 422 & 6.9 \\
\hline III & $\begin{array}{l}\text { West German labour office districts with } \\
\text { rural elements, medium-sized industry and } \\
\text { average unemployment }\end{array}$ & 63 & 820 & 16.2 & 418 & 6.9 \\
\hline IV & $\begin{array}{l}\text { West German centers with good labour } \\
\text { market prospects }\end{array}$ & 10 & 184 & 3.6 & 81 & 1.3 \\
\hline $\mathrm{V}^{2}$ & $\begin{array}{l}\text { West German labour office districts with } \\
\text { the best labour market prospects }\end{array}$ & 47 & 309 & 6.1 & 210 & 3.5 \\
\hline \multicolumn{3}{|c|}{ Total Number of Participants } & 5,064 & $100 \%$ & 6,087 & $100 \%$ \\
\hline
\end{tabular}

${ }^{1}$ Labour office districts of Berlin belong to type II. Since we do not consider these districts in the empirical analysis, they are not enlisted here.

2 Our dataset contains no information on participants in the labour office district of Donauwörth. Therefore, this district is excluded from the classification. 